\title{
Diagnóstico multidimensional y morbilidad de las cooperativas de producción en México: un estudio descriptivo y explicativo de las áreas de oportunidad de las cooperativas de la región de la costa de Oaxaca
}

(Multidimensional diagnosis and morbidity of the production cooperatives in Mexico: a descriptive and explanatory study of the opportunity areas of the cooperatives of the Oaxaca coast region)

José Luis Sergio Sosa González

Benemérita Universidad Autónoma de Puebla (México)

Sumario: I. Introducción. II. Material y métodos. III. Morbilidad y áreas de oportunidad de las cooperativas de la Región de la Costa de Oaxaca. IV. Causas sistémicas de la morbilidad y áreas de oportunidad encontradas. V. Conclusiones. VI. Referencias. VII. Anexo uno Cédula de Evaluación Diagnóstica.

Summary: I. Introduction. II. Material and methods. III. Morbidity and areas of opportunity for cooperatives in the region of Costa de Oaxaca. IV. Systemic causes of morbidity and areas of opportunity found. V. Conclusions. VI. References. VII. Appendix one Diagnostic Evaluation Form.

Resumen: En este trabajo se describen las diez principales deficiencias o áreas de oportunidad que afectan el desarrollo de treinta cooperativas de producción de la Región de la Costa de Oaxaca en México, abarcando las dimensiones normativa-institucional, social, económica, administrativa, técnica y política a partir de considerar que los fenómenos de la realidad son multidimensionales. Asimismo, a partir del análisis de la literatura teórica reciente en el área de las Ciencias Sociales y Económico Administrativas, se identifican seis causas estratégicas externas de fondo de los problemas encontrados: 1) Exce-

1 Doctor en Desarrollo Regional, Profesor-investigador adscrito a la Facultad de Administración de la Benemérita Universidad Autónoma de Puebla (BUAP), miembro del Sistema Nacional de Investigadores (SNI) del Conacyt. Domicilio institucional Av. San Claudio s/n edificio ADM1, Ciudad Universitaria, Puebla, Puebla, México, C.P. 72594, e-mail: sergio.sosa@correo.buap.mx 
siva precariedad económica de los socios cooperativistas; 2) Política educativa alienada, sin programas académicos para la economía social y el emprendimiento; 3) Deficiente arreglo normativo-institucional; 4) Deficientes y limitadas políticas públicas de apoyo a la economía social; 5) Desarrollo de una cultura individualista y oportunista en el supra-sistema, y 6) Educación formal escasa y no pertinente a las necesidades de la región.

Palabras clave: Morbilidad de las cooperativas; Diagnóstico de las cooperativas; Costa de Oaxaca; Capital humano laboral.

Abstract: This paper describes the ten main and most frequent deficiencies or opportunity areas that affect the development of thirty cooperatives of the Oaxaca Coast Region in Mexico, covering the social, economic, administrative, technical and political dimensions more institutional rules from considering that the reality phenomena are multidimensional. Likewise, based on the analysis of the theoretical literature more recent of the Social, Administrative and Economic Sciences areas, are identified six underlying strategic external causes of the problems found: 1) Excessive economic precariousness of the cooperative members; 2) Alienated educational policy, without academic programs for social economy and entrepreneurship; 3) Deficient institutional arrangement; 4) Deficient and limited public policies to support the social economy; 5) Development of an individualistic and opportunistic culture in the supra-system, and 6) Formal education scarce and not suitable to the needs of the region.

Keywords: Cooperatives morbidity; Cooperatives Diagnosis; Oaxaca Coast; Human and labor capital. 


\section{Introducción}

La economía social y el cooperativismo son opciones de desarrollo alternativo que en diversas regiones del mundo han demostrado ser efectivas para promover el desarrollo sustentable e inclusivo, sobre todo en momentos de crisis del modelo hegemónico. La importancia del cooperativismo en el mundo es notable ya que actualmente existen alrededor de tres millones de organizaciones cooperativas que dan empleo a más de ochocientos millones de personas, generan ingresos anuales de 2.1 trillones de dólares y benefician de manera directa o indirecta a más de tres mil millones de personas (Kliksberg, 2012 y Alianza Cooperativa Internacional ACl, 2018).

Sobre las bondades del modelo cooperativo y su importancia en la construcción de una economía más humana, sustentable e incluyente, la Alianza Cooperativa Internacional destaca que «El modelo de negocio cooperativo se basa en valores y principios éticos que dan prioridad a las necesidades y aspiraciones de sus miembros por delante del puro y simple objetivo de maximizar la utilidad financiera. A través de la autoayuda y del empoderamiento, reinvirtiendo en sus comunidades y preocupándose por el bienestar de las personas y del mundo en el que vivimos, las cooperativas adoptan una visión a largo plazo sobre el crecimiento económico sostenible, el desarrollo social y la responsabilidad medioambiental» (ACl, 2018:5).

Desafortunadamente, la economía social y el cooperativismo han sido relativamente poco estudiados, en comparación con las corporaciones privadas y las organizaciones gubernamentales, especialmente en relación a la «morbilidad» entendida como la incidencia de enfermedades o disfunciones de un organismo. Lo que se ha estudiado del cooperativismo tiende a centrarse en los llamados "casos exitosos» que abarcan un grupo muy reducido de cooperativas en el mundo que han tenido un destacado desarrollo y se han considerado modelos a seguir; sin embargo, se puede afirmar que se puede aprender más de los fracasos que de los éxitos cooperativistas, sobre todo si los fracasos superan por lo menos en un número de setenta a uno a los éxitos de este tipo de organizaciones. Considerando que la morbilidad lleva a la mortalidad de los organismos, se considera necesario estudiar las disfunciones, problemas o áreas de oportunidad más comunes de las cooperativas y sobre todo las causas de fondo de la morbilidad y mortalidad de estas organizaciones. Esto, como requisito previo para el diseño o rediseño de las políticas públicas de apoyo a la economía social. Sólo así se puede garantizar un diseño inteligente y una implementación efectiva de las políticas respectivas. Por el contrario, centrarse en el estudio de 
casos exitosos, equivale a tratar de prepararse para resolver una pandemia humana estudiando únicamente a las personas que están sanas. Si se quiere generar conocimiento sobre cómo fortalecer el cooperativismo, se debe hacer énfasis en estudiar estas variables con un énfasis en las causas de fondo de las mismas.

Se puede suponer que la morbilidad de las cooperativas las lleva, tarde o temprano, al fracaso y extinción de las mismas. El fracaso se puede entender como el hecho de que estas organizaciones no logren satisfacer en lo mínimo las necesidades de sostenibilidad económica de sus miembros, generando empleo, ingresos u otro tipo de beneficios económicos y sociales de manera constante y suficiente para sus socios; asimismo, que no logren cumplir su propósito de mantener en el tiempo una actividad de producción y comercialización, según su giro específico, sin pérdidas financieras. Esto, independientemente de beneficiar o no a la comunidad y al medio ambiente, ya que esto es también parte de la naturaleza de las cooperativas. Sobre el fracaso, desaparición o «mortalidad» de las Cooperativas, todo parece indicar que no existen datos confiables en México y el mundo, sin embargo, se puede inferir la magnitud de este fenómeno al ubicarlas dentro de las Micro, Pequeñas y Medianas Empresas, mejor conocidas como MiPyMEs. En el caso de México, la mortalidad de las MiPyMEs a nivel nacional es de alrededor del $65 \%$ antes de los primeros cinco años de operación (INEGI, 2015). Sin embargo, considerando que en general la problemática de las Cooperativas tiende a ser más compleja que las MiPyMES privadas, sobre todo por problemas de capital humano, financiamiento y gobernanza interna, se puede suponer que la mortalidad sea mayor. En el caso de la Costa de Oaxaca, un estudio preliminar reciente señala una mortalidad de alrededor del 90\% de las cooperativas (Sosa, Gómez, Carmona y Medel, 2019).

Con relación a la morbilidad y áreas de oportunidad de las cooperativas, una revisión bibliográfica muestra que tampoco existen estudios suficientes sobre el tema, por lo menos en México. Esto, elimina la posibilidad de que el gobierno impulse políticas públicas efectivas que aporten de manera inteligente al fortalecimiento del cooperativismo y la economía social. Asimismo, se debe señalar la carencia de planes de estudios o currículos académicos sobre administración cooperativa en casi todos los países del mundo. Para el caso de las cooperativas, entidades de la economía social u organismos del Tercer Sector, como suele llamárseles (Monzón, 2006), las áreas de oportunidad no pueden atenderse ya que no existe una disciplina académica que forme profesionistas de la gestión o administración social o cooperativista, con excepción de algunos pocos países, además de que la investigación no 
enfatiza en las áreas de oportunidad de este sector y mucho menos en identificar y estudiar las causas de fondo de las mismas.

Se puede considerar entonces como necesario desarrollar una visión realista y crítica del fenómeno con miras a describir los problemas principales del cooperativismo y estudiar las causas de fondo que han limitado, por lo menos en México, el desarrollo de las organizaciones del sector social de la economía. Sólo de esta forma se puede avanzar en la generación de conocimientos más confiables y acertados para impulsar el desarrollo de este sector como opción alternativa, confiable y conveniente ante la crisis del modelo económico hegemónico.

En cuanto al cooperativismo en México, según Izquierdo (2013) en el año 2000 se reportaban más de 20,000 cooperativas registradas, con un total de 469,200 socios sin considerar las cajas populares de ahorro y préstamo y las cooperativas de trabajadores. El mismo autor señala que en 2012 se calculaba que en México existían «más de 7 millones de personas relacionadas directamente con actividades cooperativas, de las cuales 5 millones aproximadamente participan en el sector de ahorro y préstamo popular» (Izquierdo, 2013: 99).

Con relación al estado de Oaxaca, según Medina y Flores (2015) para el año 2012 se reportaban 363 sociedades cooperativas registradas, con diversos giros económicos como producción agrícola, comercialización, industrialización de alimentos, transporte, servicios turísticos, hospedaje, ahorro y préstamo, entre otros. La Región de la Costa de Oaxaca abarca 44 municipios en los que se reporta la existencia de 56 cooperativas, lo que equivale al $15.43 \%$ del total de cooperativas de la entidad (Medina y Flores, 2015).

El estado de Oaxaca es el tercer estado más pobre del país y cuenta con una población de 3.97 millones de habitantes distribuidos en 570 municipios. Además, en el año 2015, esta entidad federativa llegó al primer lugar en rezago social y presenta disminución del número de cooperativas entre los años de 2015 a 2018 (Medina y Flores, 2020). La Región de la Costa de Oaxaca es una de las regiones más pobres y marginadas de ese estado, pero al mismo tiempo es una de las regiones más pobladas de Oaxaca lo cual denota la importancia de impulsar el cooperativismo como una forma de combate a la pobreza y marginación. Según Gutiérrez, Sosa y Carrillo (2015) en los últimos años el gobierno ha impulsado en esta región la creación de cooperativas para combatir la pobreza extrema, todo ello en el marco del Programa Estatal de los Humedales de la Costa de Oaxaca.

A partir de lo anterior, este trabajo tiene como objetivo describir y analizar las principales deficiencias o áreas de oportunidad de las cooperativas de la Región de la Costa de Oaxaca, en México. Asi- 
mismo, reflexionar sobre las causas sociales, económicas, administrativas, institucionales, técnicas y políticas que subyacen o dan lugar a dichas limitaciones y que deben atenderse para estar en posibilidades de emancipar la economía social.

Para cumplir con este objetivo, el trabajo se presenta dividido en tres apartados y una sección de conclusiones generales. En el primer apartado se explica el material y métodos utilizados en el estudio. En el segundo apartado se presentan los resultados de la investigación de campo, referentes a las principales áreas de oportunidad encontradas y la frecuencia de ellas. Para apreciar la magnitud del problema, este segundo apartado inicia con un análisis breve del ciclo de vida y la mortalidad de las cooperativas estudiadas. En el tercer apartado se reflexiona sobre las aportaciones teóricas que pudieran señalar las causas de fondo de los problemas encontrados. Esto último, con el propósito de establecer una agenda de investigación que permita confirmar conocimientos sobre las causas de fondo de la morbilidad de estas organizaciones en México. Finalmente, se presentan las conclusiones generales que pueden obtenerse de la investigación, enfatizando en las principales áreas de oportunidad encontradas y en las causas de fondo que se pueden inferir a partir de los marcos teóricos actuales.

\section{Material y métodos}

Para cumplir con el objetivo de la investigación se utilizó el método genético, entendido como aquel que busca identificar y separar los problemas, las causas y los síntomas. Para recabar la información necesaria, se aplicaron cincuenta entrevistas estructuradas en profundidad a informantes clave de treinta cooperativas de producción de la región de estudio; asimismo se realizó una encuesta estandarizada a 380 habitantes de las comunidades donde se ubican estas organizaciones en una proporción de $50 \%$ cooperativistas y $50 \%$ no cooperativistas. El propósito de la encuesta fue el de identificar diferencias significativas entre cooperativistas y no cooperativistas en aspectos de ingresos, escolaridad, calidad de vida, capital social y percepción de oportunismo en las actividades colectivas. Ante la falta de un padrón de cooperativas por parte de las autoridades respectivas, se utilizó el muestreo de recomendación o «bola de nieve» para contactar a los involucrados, abarcando finalmente el $54 \%$ de las cooperativas de la Región reportadas en la literatura. Las entrevistas en profundidad se aplicaron principalmente a los presidentes, secretarios y asesores de las cooperativas, apoyándose con grabación de audio 
y/o video para luego capturar los diálogos en un software de textos. Para procesar las entrevistas, se diseñó una cédula de evaluación diagnóstica para organizar y calificar de forma cualitativa los diferentes problemas o áreas de oportunidad encontrados en una escala Likert simétrica de cinco opciones (ver anexo número uno al final de éste trabajo). La encuesta se capturó y proceso en un software estadístico para identificar las diferencias entre la población cooperativista y no cooperativista. Finalmente, se realizó una investigación documental exhaustiva sobre la literatura existente para identificar las posibles causas de fondo de las áreas de oportunidad encontradas, buscando así establecer una agenda de investigación confirmatoria futura.

\section{Morbilidad y areas de oportunidad de las cooperativas de la región de la Costa de Oaxaca}

Una primera aproximación al estudio de las cooperativas de la Región de la Costa de Oaxaca muestra que el ciclo de vida de estas organizaciones es muy corto y accidentado y se puede resumir de manera general en cinco etapas: a) cohesión social inicial; b) definición del proyecto cooperativo; c) formulación técnica de los proyectos y gestión del financiamiento; d) puesta en marcha y operaciones; e) desintegración o consolidación (Sosa, et al., 2019). Sobre la mortalidad de las cooperativas en esta región, se puede decir que el $90 \%$ se encuentra en una fase de posible desintegración real. Los estudios señalan que «por lo menos la mitad de las cooperativas estudiadas dan muestras claras de haber entrado en un lento proceso de desintegración y otro $40 \%$ tienen problemas con el modelo de negocio que implementaron. En contraparte, sólo un 10\% muestra evidencia de viabilidad económica y por tanto de una posible consolidación» (Sosa, et al., 2019:18).

Considerando que el grado de mortalidad de estas cooperativas es muy alto, comparado con las MiPyMEs en general del país, y dada la importancia de la economía social, se procedió a determinar, a partir de la información recabada, las principales deficiencias o áreas de oportunidad que subyacen o dan lugar a esta mortalidad. Se diseñó una cédula para calificar cada rubro o área de oportunidad en una escala Likert simétrica de cinco opciones la cual fue llenada a partir del análisis minucioso de las entrevistas.

Las áreas de oportunidad más frecuentes y que se consideraron de mayor impacto para explicar la «mortalidad o fracaso» de las cooperativas de la región estudiada, son las que se explican a continuación, en orden de importancia: 


\subsection{Deficiente capital humano y ausencia de capital laboral para enfrentar las dificultades de un emprendimiento social}

El capital humano se puede definir como el conjunto de conocimientos, capacidades, competencias y habilidades que tienen los individuos y que les sirve para realizar actividades productivas que les permitan generar satisfactores y obtener beneficios para mejorar su calidad de vida. Un indicador muy utilizado para tratar de ponderar el capital humano es el número de años de escolaridad formal de cada individuo ya que existe la idea generalizada de que la educación formal desarrolla el capital humano. Más allá de que se esté de acuerdo o no en medir el capital humano de esa forma, lo cierto es que resulta la aproximación más sencilla y práctica. Debido a ello, en la encuesta estandarizada aplicada se incorporaron preguntas sobre la escolaridad formal de los encuestados.

Según el INEGI (2015) el grado promedio de escolaridad de la Región de la Costa de Oaxaca es de 5.6 años, lo cual significa que en promedio la escolaridad apenas alcanza el sexto año de primaria; este promedio se encuentra debajo del promedio estatal (6.9 años)y debajo del promedio nacional (8.6 años) y se puede considerar como totalmente insuficiente para lograr emprendimientos sociales exitosos debido a la complejidad que es inherente a la creación y desarrollo de cualquier empresa productiva, sea social o privada (Kliksberg y Silberstein, 2015).

Según la encuesta realizada, la escolaridad formal de los cooperativistas tiende a concentrarse entre primaria (33\%) y secundaria (34\%), mientras que un $18 \%$ reporta estudios de bachillerato, un $2 \%$ carrera técnica y un $6 \%$ estudios de licenciatura. Se puede decir que el promedio de escolaridad formal de los cooperativistas es ligeramente superior al regional y al estatal. Sin embargo, también se debe señalar que en ningún caso los estudios realizados por los miembros de las cooperativas incluyen conocimientos relacionados con emprendimientos privados o sociales o con economía social, debido a que esta temática está ausente en el currículo de todos los estudios formales de la región y el país. Esto es algo que parece suceder en varias partes del mundo, según lo documentan Martín, Fernández, Bel y Lejarriaga (2013). En otras palabras, las habilidades, conocimientos, capacidades y competencias que se requieren para asegurar el éxito de un emprendimiento social no son desarrolladas o adquiridas en la educación formal por lo que se puede afirmar que el capital humano de los cooperativistas, está completamente ajeno a las necesidades de los emprendimientos sociales y productivos de la región. 
Por otra parte, considerando que un emprendimiento social implica una gran complejidad y por tanto conocimientos y habilidades diversas, se puede afirmar que incluso los estudios de licenciatura, que no se refieren específicamente a emprendimientos privados o sociales, son insuficientes para enfrentar las exigencias de una actividad de este tipo. Con relación a la baja escolaridad formal de los cooperativistas, Consuelo Mújica Hernández, Secretaría del Consejo de Vigilancia de la Cooperativa "Turismo Alternativo Tututepec», menciona que "hay dos jóvenes que ellos estudiaron el bachillerato, de alli sólo secundaria y primaria. Hay que aprender, el presidente no sabe leer, ponga usted que no sabe ni expresarse bien pero él ha ido buscando y nos ha motivado mucho a nosotros». En el mismo sentido, Perfecto Escamilla Martínez, Secretario del Consejo de Administración de la cooperativa «Servicios Eco-turísticos de la Ventanilla» explica que "yo era el único que tenía secundaria cuando iniciamos, los demás primaria y los que entraron después ya con secundaria, algunos tienen bachillerato de los que entraron después».

Sobre el capital laboral, éste se considera como un tipo de capital humano, pero que no se adquiere en la educación formal. Este tipo de capital se puede definir como los «conocimientos, experiencias, habilidades y relaciones adquiridas a través de una relación laboral subordinada, pero relativas a procesos económicos integrales, que son susceptibles de usarse en el futuro para emprender de forma exitosa una actividad económica independiente». (Sosa, 2013:58). Se observó que alrededor del 10 a $15 \%$ de las cooperativas cuentan con miembros que en algún momento trabajaron en actividades productivas relacionadas con el proyecto productivo cooperativista. En esta condición destacan las cooperativas relacionadas con los recorridos turísticos o transporte en lancha, ya sea en las playas de la región o en las Lagunas de Chacahua, así como las cooperativas pesqueras, ya que en ambos casos existe experiencia laboral previa de algunos miembros, tal es el caso de las cooperativas: Producción Pesquera Ribereña de Manialtepec; Flama Extraña; El Lagartero Tututepec y Faro de Chacahua.

En los casos anteriores, los cooperativistas que tienen experiencia previa contribuyen al éxito de la cooperativa, sin embargo, también tienen limitaciones debido a que su experiencia no es integral sino centrada en actividades productivas y no tienen experiencia en áreas estratégicas como son agregación de valor, negocios, comercialización, finanzas y mercadotecnia. En otras palabras, no cuentan con capital laboral de emprendimiento, sino únicamente con experiencia laboral sobre actividades parciales de una organización productiva. 
Las políticas públicas de apoyo a los emprendimientos productivos en México han reconocido de alguna forma la problemática anterior, por lo que desde hace décadas algunas Secretarías de Estado han impulsado la figura del Prestador de Servicios Profesionales (PSPs) como sustituto a los técnicos extensionistas que trabajaban al servicio del Estado antes de la época neoliberal. Sin embargo, la función de los despachos privados de PSPs no ha generado los resultados esperado, tal y como se observa a continuación.

\subsection{Asesoría fragmentada y falta de acompañamiento profesional}

La asesoría y el acompañamiento profesional han sido considerados por algunos estudiosos como aspectos fundamentales sin e qua non para el éxito de los emprendimientos productivos, sobre todo en el caso de grupos sociales excluidos (Aguilar, Altamirano, Reyes y Rendón, 2010) y (Abiétar, Ros-garrido y Marhuenda, 2018). Sobre la necesidad del acompañamiento profesional, se observó que los emprendimientos sociales que dan lugar a las cooperativas estudiadas presentan un grado de complejidad muy alto pues se trata realmente de diseñar, construir y desarrollar una organización productiva prácticamente de nada, con todas las complicaciones que ello puede tener. Esto exige conocimientos y habilidades muy diversas como son conocimientos de índole administrativo, financiero, comercial, técnico productivo, adquisiciones, entre otros; así como habilidades de análisis, síntesis, prospectiva, comunicación, relaciones humanas, manejo de conflictos, entre otras. Sin embargo, como se describió en el punto anterior, prácticamente el $100 \%$ de los miembros de las cooperativas de la Región no tienen estudios profesionales o técnicos donde se adquieran estos conocimientos y habilidades.

Debido a esto, la mayoría de los grupos buscan asesoría externa con quienes consideran pueden orientarlos de mejor manera. Para ello recurren o son contactados por funcionarios públicos, despachos privados de PSPs, Redes de Cooperativas o activistas individuales promotores de la economía social en la región. Sin embargo, la relación que se establece con estos facilitadores o asesores externos es meramente circunstancial, esporádica y poco eficaz, con excepción de las Redes de Cooperativas que observan cierta continuidad en la relación. Sobre esto, Lucia Santos López, Presidenta de la Cooperativa Flama Extraña señaló que «nos afecta que no tenemos quien nos apoye o quien nos asesore para poder organizarnos bien y para trabajar como debe de ser, como cooperativa. Sin acompañamiento no vale uno nada». 
Incluyendo las Redes de Cooperativas, los facilitadores o asesores externos demuestran poco compromiso y conocimiento de la evolución de las cooperativas y de los problemas que enfrentan. Normalmente se limitan a ofrecer asesoría muy específica, únicamente para gestionar asuntos muy concretos, por ejemplo: para llenar un expediente y realizar un trámite administrativo; elaborar un proyecto de inversión que parezca viable, de tal manera que se obtenga financiamiento gubernamental; inscribirlos en el padrón de la autoridad fiscal; gestionar un permiso oficial específico; impartir un curso de capacitación sobre un tema muy concreto; entre otros.

Por cada uno de estos servicios, los facilitadores reciben una cuota específica que implica su ganancia. Sin embargo, no hay un acompañamiento integral ni permanente en el que se apoye a los cooperativistas para enfrentar los diversos obstáculos organizacionales, técnicos, administrativos, humanos o financieros que implica un emprendimiento social, lo que repercute negativamente en la viabilidad de las cooperativas. Sobre los servicios de asesoría recibidos, José Emilio Pascual Carreño, miembro de la Cooperativa El Cabonanche, señala que «aquí hay varios que se dedican como asesores, técnicos, nos han dado cursos y todo eso y han hecho la gestoría para hacer los trámites con las dependencias y ya ellos agarran una parte, por ejemplo en lo de las cabañas, tuvimos un biólogo, él era nuestro asesor, le pagamos 70 mil pesos, eran sus honorarios por cada millón obtenido del gobierno».

Por otra parte, aquellas cooperativas que logran la asesoría más permanente de las Redes o Federaciones de Cooperativas, tienden a poder enfrentar de manera más exitosa los problemas cotidianos de operación y puesta en marcha del proyecto cooperativo. Esto, debido a que estas organizaciones de segundo piso procuran recibir e impartir más cursos de capacitación, aunque el acompañamiento sigue siendo limitado e insuficiente.

Sólo seis de las cooperativas estudiadas (20\%) cuentan con la asesoría de alguna organización de segundo piso. Dentro de estas Redes o Fundaciones se señalan a la Red de los Humedales de la Costa de Oaxaca (RHCO) que asesora a las cooperativas "Producción y Servicios Ecoturisticos Playa Del Cacalote; Producción y Servicios Ecoturisticos Playa La Encomienda; Servicios Ecoturisticos La Ventanilla y El Castillo Guelaguichi, Tehuantepec. Asimismo, la Red Comunitaria Lagunas de Chacahua $(\mathrm{RCLCH})$ que asesora a la cooperativa «Turismo Alternativo Tututepec». Finalmente, la Fundación Sembrando Trabajo (FST) que asesora a la cooperativa "Productoras Ecológicas de El Tomatal».

Sobre el apoyo de las organizaciones de segundo piso, Ernesto García Ramírez, Presidente de la Cooperativa Playa Tilapia comenta que 
«con la red está bien porque estamos organizados, solos es más trabajoso porque no nos atienden, no nos hacen caso de ninguna solicitud, o si nos hacen caso es muy tardado, ya con la red no, porque como estamos organizados con varias cooperativas ellos meten varias solicitudes, ya ellos van personalmente a Oaxaca o a México ya los atienden más a ellos».

El deficiente capital humano, la ausencia de capital laboral de emprendimiento y la ausencia casi total de una asesoría y acompañamiento integral, se puede decir que son los aspectos que más inciden en el fracaso de las cooperativas de la región estudiada. Ante ello, la capacitación adecuada y constante para los cooperativistas podría ser una opción conveniente que los habilitara para enfrentar los retos que implican los emprendimientos sociales.

\subsection{Capacitación insuficiente y no pertinente a las necesidades de las cooperativas}

La capacitación a organizaciones productivas conformadas por grupos marginados es una acción concreta y evidente que realizan los ámbitos de gobierno federal, estatal y municipal en México. Se busca habilitar a las personas y grupos para la productividad y la competitividad y para insertarse al mercado laboral y productivo. Sin embargo, la cobertura y pertinencia de esta capacitación se aprecia con graves deficiencias sobre todo en su ejercicio en las cooperativas de la región estudiada.

Si bien es cierto que varias cooperativas reportan haber recibido cursos de capacitación, se aprecia claramente que estos cursos no tienen un vínculo directo con los problemas y retos que enfrentan estas organizaciones. Se pudo constatar que ninguna cooperativa ha recibido capacitación sobre agregación de valor, gestión financiera, mercadotecnia, trámites administrativos, resolución de conflictos u otra temática que se relacione con los emprendimientos privados o sociales. De la misma forma, ninguna cooperativa reporta haber recibido algún curso sobre cooperativismo o sus principios, de hecho en las entrevistas se observa que prácticamente los desconocen.

Los pocos cursos de capacitación que reportan haber recibido se refieren únicamente a aspectos técnicos muy concretos tales como: tratar bien al turista; concientización sobre el turismo; seguridad en las lanchas; conservación de tortugas; manejo de recursos en áreas naturales; guías ambientales y de turistas; entre otros, los cuales aunque se pueden considerar positivos, lo cierto es que los confinan a tener una 
visión fragmentada de los procesos económicos y por tanto los condenan al fracaso como emprendedores sociales.

Sobre cursos de capacitación más acordes a sus necesidades, únicamente la cooperativa "Turismo Alternativo Tututepec» reporta haber recibido un curso sobre cómo manejar un negocio. Asimismo, la cooperativa "Servicios Eco-turísticos de la Ventanilla» señala haber recibido un curso sobre proyectos de inversión. Este tipo de cursos se podrían considerar más vinculados y útiles para la problemática que enfrenta un emprendimiento social o privado.

Con relación a la falta de cursos estratégicos de capacitación para impulsar una organización productiva privada o social, Carmelo Silva Hernández, Secretario General de la cooperativa «Producción Pesquera Ribereña de Manialtepec» explica que «No nos han dado ningún curso de esos, hubo una ocasión, cuando nos dieron las lanchas, nos dieron asesorías solamente para el turismo, ni para pesca no nos han dado». Asimismo, Arturo Méndez y Fermín Amadeo García Ramírez, asesores independientes del movimiento cooperativista, subrayan que «el gobierno no capacita a las cooperativas ni a los técnicos que apoyan a las cooperativas...por supuesto, necesitamos que el gobierno nos capacite para que podamos nosotros dar un valor agregado a nuestro producto...es importante que el gobierno nos capacite para saber dónde hay mercado para el pescador, para los trámites, para los proyectos, para bajar recursos, para ver cómo puede el sector pesquero desarrollarse; solos no podemos».

Como se puede observar hasta aquí, el panorama de las cooperativas de la Costa de Oaxaca no es nada alentador. Los tres aspectos analizados hasta este momento condenan a estas organizaciones al fracaso por estar relacionadas con el activo más importante de cualquier organización, es decir "el capital humano», considerado así por la teoría respectiva ${ }^{2}$. Este activo fundamental puede acrecentarse, disminuirse o sustituirse en función de la capacitación, la escolaridad formal, la experiencia laboral y el acompañamiento por parte de expertos, aspectos en los cuales las organizaciones estudiadas muestran grandes deficiencias.

2 La Teoría del Capital Humano señala que la productividad y el crecimiento económico de una región (y de sus organizaciones) están determinados por el agregado de conocimientos, capacidades y aptitudes de los individuos involucrados en los procesos productivos. Independientemente de estar de acuerdo o no con esta afirmación, lo cierto es que ésta es una teoría muy aceptada en el ámbito académico. Para mayor información, se puede consultar Villalobos y Pedroza (2009) y Ciruela (2009). 
Con relación a la importancia de estos elementos, Sánchez, López, Bel Durán y Lejarriaga, (2018) plantean que la deficiencia de capital humano y más específicamente la falta de «formación en emprendimiento social», se pueden considerar como el germen o la causa principal que, de una u otra forma, determina las deficiencias o áreas de oportunidad de las cooperativas, por lo que podrían explicar las demás áreas de oportunidad que se analizan a continuación.

\subsection{Proyectos productivos no viables ni pertinentes desde el punto de vista económico y técnico}

Fue posible apreciar que la mayoría de los proyectos productivos sobre los que se fundamentó la creación de las cooperativas de la Región no muestran ser viables ni pertinentes desde el punto de vista económico y técnico. Aún sin necesidad de ser expertos en evaluación de proyectos, resulta evidente que la mayoría de las actividades productivas de las cooperativas no corresponden con las necesidades del mercado y los procesos técnicos no aseguran la producción necesaria.

Un ejemplo destacado de lo anterior, lo constituye la "Cooperativa de Turismo Alternativo Tututepec» de la comunidad de «La Pastoría» en el municipio de Tututepec. Esta cooperativa obtuvo financiamiento gubernamental, a fondo perdido ${ }^{3}$, por más de dos millones de pesos en el año 2013, los cuales destinó a la construcción y equipamiento de un restaurante grande, adquisición de mobiliario de madera labrada, así como construcción y equipamiento de cabañas para hospedaje junto a una de las Lagunas de Chacahua.

El proyecto cooperativo fue concebido para proporcionar servicios de hospedaje, alimentación y esparcimiento al turismo alternativo que desea conocer el proceso artesanal de producción de sal en grano que se realiza en las orillas de la laguna. Desafortunadamente, las grandes y costosas instalaciones de esta cooperativa no generan ingresos para los cooperativistas ya que los turistas no asisten al lugar por diversas razones entre las que destacan las siguientes: a) lo insalubre de la laguna, que genera un hedor fétido la mayor parte del tiempo, dando la impresión de que fueran aguas de drenaje o un pantano más que una laguna; b) el difícil acceso a las cabañas, ubicadas sobre una cima,

3 La modalidad "a fondo perdido» indica que los beneficiarios del apoyo gubernamental no deben pagar o regresar los recursos recibidos, únicamente están obligados a demostrar que se invirtieron efectivamente en aquellos rubros para los que fueron proporcionados. 
que no cuentan con acceso por escaleras sino sólo una vereda de tierra, siendo muy común que los usuarios resbalen constantemente en la misma antes de llegar a sus habitaciones, además de que no cuentan con servicio de agua ni se terminaron de construir por falta de recursos; c) el acceso a la comunidad y posteriormente a las instalaciones construidas (cabañas y restaurante), a través de una vereda, sin señalamientos, donde difícilmente entran los automóviles y se corre el riesgo de atascarse en época de lluvias; d) El espacio donde se obtiene la sal en grano se encuentra aún más alejado, entre huertos y pastizales de muy difícil acceso. El turista no puede resguardarse del sol y el calor que llega a superar los cuarenta grados centígrados. La demostración que recibe el turista sobre el proceso artesanal de obtención de la sal, tarda más de una hora, bajo el sol en un lugar totalmente despoblado y lejos de la civilización. Todo esto hace inviable, desde el punto de vista económico y técnico este proyecto de servicios.

Algo parecido sucede con otros proyectos productivos para turismo alternativo que cuentan con infraestructura de hospedaje y restaurantes, como es el caso de las cooperativas «El Cabonanche», «Flama Extraña», "La Ventanilla» y "Lagarto Real». Las instalaciones tienden a ser poco confortables y se ubican en lugares poco visitados y de difícil acceso por lo que constantemente se encuentran desocupadas y no generan los ingresos necesarios. Sobre esto, Lucia Santo López, presidenta de la "Cooperativa Flama Extraña», explica su experiencia señalando que «las cabañas eran para restaurante y para hospedar a la gente, pero como apenas comenzábamos sólo nos preguntaban. Lo mínimo eran 100 pesos la noche... no generaba dinero, sólo invertíamos y eso era lo que veían los compañeros, que todo el tiempo íbamos a estar así, por eso muchos se salieron».

Por otra parte, también destacan las cooperativas que han obtenido fondos para construir estanques para producción de peces ya sea para venta o autoconsumo. Estos estanques terminan usándose para otros fines debido a que, por diversas cuestiones técnicas, climáticas y de capacitación no se logra la producción esperada. Con relación a esto, María Velasco Ramírez, Presidenta del Consejo de Vigilancia de la Cooperativa «Sirenas del Ángel» explica que «un proyecto viable de acuacultura necesita mínimo ocho estanques, es como las gallinas, pero qué hace el gobierno para justificar dinero, eso sí son tranzas del gobierno que yo he visto... les da 200 mil pesos cuando son proyectos de mínimo 400 mil, ... les hacen dos o tres estanques y el productor termina comiéndose el pescado porque ya no hay más estanques para que la producción siga... esos tanques terminan de albercas o de chapoteaderos para los niños porque no les dan seguimiento...no les 
mandan un técnico que les diga cómo darles de comer, la alimentación, oxigenación del agua, los cuidados... ese es el error que tiene SAGARPA y no les dan seguimiento y los dejan».

Finalmente pueden señalarse cooperativas pesqueras, aunque son las menos, que han gestionado recursos para adquirir cámaras frigoríficas para congelar la pesca, sin embargo, frecuentemente tampoco llegan a utilizarse y son abandonadas pues el problema de fondo se relaciona más con el acceso a mercados y la agregación de valor ${ }^{4}$ a los productos que con el mero almacenamiento. Sobre esta situación, Pablo Cosme Ríos, Presidente de la cooperativa de producción pesquera «Paraíso Escondido» explica que «durante la época de Salinas de Gortari muchas cooperativas se beneficiaron, hubo varios proyectos, dieron todo el equipo que necesitaban, embarcaciones, cámaras frigoríficas, todo, había mucho dinero; pero al final nada de eso funcionó y se fue a la quiebra».

\subsection{Falta de financiamiento e incapacidad de acceder a los apoyos gubernamentales}

Dado que la Región de la Costa de Oaxaca es una de las más pobres del país, el financiamiento externo a través de recursos públicos es fundamental para iniciar las cooperativas. Sin embargo, se identificó que diez de las treinta cooperativas estudiadas (33\%) no han recibido financiamiento público, aunque todas lo han buscado permanentemente. Asimismo, el financiamiento recibido por el resto de las cooperativas es muy desigual yendo desde apoyos mínimos en especie hasta recursos a fondo perdido por varios millones de pesos. Ejem-

4 La «Agregación de Valor» es considerada por algunos autores como la estrategia por excelencia para mejorar los ingresos y la calidad de vida de productores primarios. Se compone de cinco tipos de utilidades o modalidades de agregación de valor: La utilidad de forma consiste en transformar los productos o desarrollar características físico-químicas o biológicas en función de lo que el mercado necesita; la utilidad de tiempo consiste en ofrecer los productos en épocas donde escasean y por tanto el precio es más alto, obviamente esto implica la preservación del producto o su producción planeada (por ejemplo en estanques); la utilidad de lugar se relaciona con su colocación en lugares donde es más demandado el producto y por tanto puede ser vendido a un precio más alto; la utilidad de posesión facilita las transacciones comerciales con facilidades de pago, financiamiento, pago con medios electrónicos, entre otros; la utilidad de información es aquella que difunde información sobre características del producto y su disponibilidad para facilitar e incentivar la comercialización. Para mayor información consultar (Sosa, Escobedo y Gutiérrez, 2014 y Caldentey, 2004). 
plos de cooperativas que han recibido apoyos menores son aquellas que se dedican a la conservación de especies en peligro de extinción (específicamente tortugas), éstas normalmente reciben una cuatrimoto por cooperativa y recursos periódicos para el combustible de la misma. Alguna de estas cooperativas recibió únicamente apoyo para colocar señalamientos. En contraparte, las cooperativas que destacan por el monto de financiamiento público recibido son aquellas dedicadas a servicios turísticos de hospedaje y alimentación con apoyos para construir y equipar cabañas y restaurantes.

La falta de financiamiento público y la disparidad en los apoyos recibidos, parece ser el resultado de dos grupos de factores: los institucionales y los sociales. Los factores institucionales, para este caso, son los que tienen que ver con los procesos burocráticos y la discrecionalidad de autoridades gubernamentales al ejercer fondos públicos para apoyar este tipo de organizaciones. Lo limitado del presupuesto público, la corrupción, el nepotismo y la simulación por parte de la burocracia y autoridades son aspectos señalados por los cooperativistas como las causas de no acceder a apoyos públicos. Sobre esto, Arturo Méndez, asesor cooperativista y ex dirigente de la «Federación de Cooperativas Pesqueras del Estado de Oaxaca», señala que "el presupuesto es mínimo comparado con las necesidades de todas las organizaciones del país, por lo tanto, lo regulan vía las famosas reglas de operación...todas las cooperativas van por esta lana, tienen que tener todos los papeles en orden que son muchísimos, curiosamente a veces cuando cumpliste con los requisitos, la ventanilla ya se cerró, no entraste...otra es que si te falta un requisito ya no entraste, y de las que se cuelan que cumplieron con todo, ahí va la mano del delegado... ha pues es que conozco, es mi compadre y así el recurso va para sus cuates... mientras no cambien las reglas del juego, la operación de honestidad, nada va a funcionar».

Por otra parte, los factores sociales se refieren a la falta de conocimientos y experiencia de los cooperativistas y de los asesores en el tema de formulación de proyectos sociales y gestión de fondos públicos. Se pudo apreciar que existe un limitado e ineficiente mercado de facilitadores y prestadores de servicios profesionales que fungen como asesores y gestores de las cooperativas, pero de los cuales la gran mayoría no cuenta con la experiencia ni preparación para gestionar de forma exitosa fondos gubernamentales ni para asesorar emprendimientos sociales. Esto se pudo apreciar en el hecho de que la mayoría fracasa en la gestión de fondos y en el tipo de proyectos productivos que proponen a los cooperativistas. Sobre este aspecto, Carmelo Silva Hernández, Secretario General de la Cooperativa de Producción Pes- 
quera Ribereña de Manialtepec, explica que «eso nos ha pasado con algunos proyectistas, que vienen y nos dicen que hay recursos del gobierno y que ellos los pueden bajar y que nos van a apoyar, y la verdad nos han sacado dinero, nos han engañado por que al final no logran nada. Ahora si viene alguien ya tratamos de no darle dinero sino que buscamos personas que del mismo proyecto obtengan para ellos». En el mismo sentido, Oscar Rodríguez Marcial, Presidente de la Cooperativa Producción y Servicios Eco-turísticos Playa del Cacalote, señala que «uno de los problemas es que no tenemos recursos, hemos gestionado y no tenemos apoyo. Trabajamos con las tortugas porque nos nace de corazón, pero no tenemos apoyo de alguna institución o de alguna fundación... hemos metido gestión a SEMARNAT, a CONAGUA, SAGARPA, pero no ha salido nada».

Las cooperativas que cuentan con apoyo de las organizaciones de segundo piso, tienen mayor probabilidad de obtener apoyos gubernamentales ya que los técnicos de las federaciones tienden a ser ex funcionarios de gobierno que conocen mejor las reglas de operación de los programas gubernamentales de apoyo. Desafortunadamente, además de ser únicamente dos federaciones las que tiene actividad en la región, resulta que el esquema de asesoría y acompañamiento es totalmente fragmentado en el sentido de que sólo se les apoya en el diseño del proyecto, llenado de expedientes y gestión de fondos, sin que las cooperativas reciban la capacitación necesaria para enfrentar los retos y problemas organizacionales, administrativos, financieros, mercadológicos, técnicos y demás que implica un emprendimiento social productivo.

3.6. Relaciones clientelares con las organizaciones de segundo piso del sector

El clientelismo se puede entender como una relación de dependencia y subordinación no reconocida formal u oficialmente pero que opera en la realidad. Se define, según Bobbio, Mateucci y Pasquino (2013: 234-235) como «una relación de dependencia económica y politica... entre sujetos de estatus diverso... que establece una red de fidelidades personales...sustentada por el uso de los recursos estatales». En esta relación se comparten beneficios, normalmente de forma desigual, pero no se comparten intereses formales de fondo.

Las Redes y Federaciones de Cooperativas (RC) y las Organizaciones de la Sociedad Civil (OSC) que se pueden considerar organizaciones de segundo piso y que han tenido presencia histórica o actual en la 
región, son las siguientes: a) Red de los Humedales de la Costa de Oaxaca; b) Red Lagunas de Chacahua; c) Fondo Oaxaqueño para la Conservación de la Naturaleza; d) Fundación Sembrando Trabajo y e) Ecosolar A.C. conocido actualmente como Red de Organizaciones Sociales y Comunitarias Bioplaneta.

Se pudo observar que cuando se encuentran involucrados actores con grandes disparidades sociales y económicas, como es el caso de los socios cooperativistas con las organizaciones de segundo piso, tienden a establecerse relaciones clientelares, sobre todo cuando éstas últimas pierden su vocación social y se inclinan por el lucro. En este caso, la relación clientelar tiene efectos negativos en el desarrollo de las cooperativas ya que éstas tienden a subordinarse en esta relación desigual, convirtiéndose en actores secundarios y dependientes de las organizaciones de segundo piso que son las que gestionan y reciben los apoyos y financiamientos del gobierno y otros organismos.

Sobre este aspecto, Luis Antonio Fuentes, Secretario de la Cooperativa "Lagarto Real» señala que "en las cooperativas de la Costa ha pasado mucho, por el «liderismo» de una sola organización, debido a que las cooperativas siguen funcionando como una especie de lavado de dinero con las asociaciones civiles, porque bajan muchos recursos, tienen posibilidad de adentrarse a las embajadas, organizaciones a nivel internacional con el doble nombre de las cooperativas, pero a final de cuentas ellos son los que se quedan con el 60 o con el 70\% de todos esos apoyos y es una mínima parte lo que dan. Por su parte los cooperativistas dicen «si me vas a dar todo regalado pues yo no digo nada, me quedo callado», entonces, esas organizaciones en muy poco tiempo han crecido, se han hecho populares porque le han estado exprimiendo a todas las cooperativas de la zona».

Evidentemente, no se puede generalizar la relación clientelar entre las cooperativas y las organizaciones de segundo piso, sino que probablemente en algunos casos la relación tiende a ser más equitativa o simbiótica; sin embargo, lo cierto es que si éste fenómeno se presenta es debido a lagunas $u$ omisiones graves en las reglas de operación de los programas o políticas de donde provienen los recursos públicos. En todo caso, se requeriría una revisión y en su caso adaptación de las normas respectivas para evitar este tipo de disfunciones.

\subsection{Lucha interna por el poder y oportunismo}

La frecuencia y complejidad de los conflictos internos en las organizaciones en general ha sido reconocida por diversos estudiosos, lo que 
ha llevado a desarrollar robustas corrientes teóricas para entender y atender este problema ${ }^{5}$. Las cooperativas estudiadas no se encuentran ajenas a la problemática del conflicto intra-organizacional y a la lucha por el control de la organización. Se pudo apreciar que este es un problema que consume gran parte de la energía y capacidades de sus integrantes. Se observó que el conflicto tiende a aparecer e intensificarse cuando se presentan dos factores específicos combinados: a) cuando ha habido apoyos gubernamentales para adquirir activos fijos valiosos y b) cuando la cooperativa no ha podido desarrollarse económicamente y tiende a la desintegración.

La combinación de estos factores desata una lucha interna por controlar los cargos u órganos decisorios de la organización. El mecanismo de fondo que parece activar el conflicto, es el intento de algunos por apropiarse de los activos de la organización y privatizar de alguna forma lo que se ha obtenido a partir del trabajo de todos. Este fenómeno ya se ha identificado en otras regiones con presencia importante de cooperativas y se le ha identificado como "oportunismo organizacional» (Sosa, 2013). El oportunismo, entendido como la acción de apropiarse de los beneficios generados por el trabajo colectivo, parece presentarse ante el hecho de que, en casi todos los casos, los activos no pueden dividirse equitativamente entre los socios pues se trata de bienes unitarios. Algunos de esos bienes son construcciones, equipo de producción, equipo de transporte, muebles, entre otros, que no pueden dividirse equitativamente entre el número de cooperativistas sin destruirlos y que tampoco es fácil venderlos a precios aceptables para luego repartir el dinero.

Cuando los dos factores anteriores están presentes y los bienes no son fácilmente divisibles, la actitud de oportunismo aumenta y termina canalizando los esfuerzos y capacidades de los cooperativistas hacia la lucha interna, en lugar de enfocar sus capacidades hacia la solución de los problemas de fondo y al desarrollo de la organización productiva. La lucha interna por el poder y por la apropiación de los activos de la cooperativa, termina sumiendo a la misma en una larga agonía pues el marco normativo y la falta de consensos imposibilitan soluciones de corto plazo. Con relación a esto, en la comunidad de La Pastoría, municipio de Tututepec, se encontraron vestigios de antiguas cooperati-

5 Entre las corrientes teóricas que se han desarrollado para atender y entender el conflicto organizacional se pueden mencionar la Escuela del Comportamiento Humano, la Escuela Psico-sociológica, la Escuela Neo-humano Relacionista, la escuela del Desarrollo Organizacional así como la Escuela Neo-institucional, entre otras. Mayor información en Robbins y Judge (2013), Arnoletto (2009) y Davis y Newstrom (2002). 
vas pesqueras donde cámaras frigoríficas y embarcaciones terminaron siendo abandonadas luego de largo tiempo de conflictos internos y luchas infructuosas por privatizar los activos fijos de las cooperativas.

Cuando los anteriores elementos no están presentes en una cooperativa, el conflicto interno tiende a ser menor pero aún logra impactar la opinión sobre el oportunismo en las cooperativas. En la encuesta aplicada, pudo observarse que hay una diferencia, mínima pero estadística significativa, en la percepción de oportunismo, siendo mayor entre cooperativistas que entre no cooperativistas. Esto llama la atención pues podría indicar que el oportunismo generado por el estrés del fracaso de las cooperativas está afectando el capital social comunitario. En todo caso esto llevaría a ampliar la agenda de investigación para conocer en qué condiciones aumenta o disminuye el oportunismo y cuáles son las consecuencias para el capital social de las cooperativas y las comunidades involucradas.

\subsection{Falta de permisos de operación y dificultad para gestionarlos}

Los cooperativistas normalmente requieren de un permiso de la autoridad correspondiente para realizar su actividad productiva, pero es muy difícil obtenerlo. En este aspecto, destacan las cooperativas pesqueras que requieren un permiso de la «Capitanía de Puerto» para poder realizar la pesca ribereña de la que subsisten. Sin embargo, los permisos son cada vez más limitados y por tanto difíciles de obtener. Es precisamente esto lo que motiva a algunos pescadores a agruparse en cooperativas para sufragar de manera conjunta el pago de gestores y el costo del propio permiso. La mayoría de las cooperativas pesqueras terminan trabajando con un solo permiso para diversas embarcaciones y socios, pero en muchos otros casos se trabaja sin permisos. En estos casos, las multas que deben pagar cuando son sorprendidos por la autoridad pescando, sin el permiso correspondiente, son muy cuantiosas y afectan la economía de los cooperativistas y de la cooperativa en general considerando que ésta se sostiene con las aportaciones de todos.

Por otro lado, las cooperativas de transporte turístico, de paseos en lancha y de pesca deportiva, se encuentran en condiciones parecidas. Todos los socios de la cooperativa trabajan con un solo permiso y existe una proporción de cooperativas que trabajan sin permiso y otra proporción trabaja con permisos vencidos. Sobre este aspecto, Carmelo Silva Hernández, Secretario General de la Cooperativa Producción Pesquera Ribereña de Manialtepec explica que «todas las cooperativas están atoradas por los trámites. En el municipio se hizo 
un padrón de todas las cooperativas y todas las cooperativas tienen el mismo problema, que no están vigentes con sus permisos, con sus actas, todos tienen problemas en eso». En el mismo sentido, Consuelo Mujica Hernández, Secretaria del Consejo de Vigilancia de la Cooperativa Turismo Alternativo Tututepec, señala que «las dependencias ponen muchos trámites, la burocracia es lo que hace perder el tiempo a las cooperativas, que dijeran, no este permiso te lo voy a dar tal día, ven tal día y que el permiso ya esté hecho «tengan señores, vayan a trabajar», pero lo que hacen a uno es perder mucho tiempo, no sé si con la intención de no dar un permiso, de no dar un apoyo, ponen muchas trabas como decimos aquí, para que solucionen una cosa pequeñita».

En contraparte, existe la opinión generalizada, por parte de los entrevistados, sobre que existe favoritismo de la autoridad para expedir permisos a las corporaciones y grandes empresas privadas, relacionadas con la pesca, mientras que las organizaciones sociales son marginadas de alguna forma.

\subsection{Publicidad y promoción deficientes}

Dado que las cooperativas son organizaciones sociales productivas que compiten en un mercado de bienes y servicios, la publicidad y promoción que realizan es fundamental para su éxito. A partir de la observación, pudo corroborarse que la gran mayoría de las cooperativas estudiadas presentan deficiencias graves en aspectos de publicidad y promoción. Destaca que ninguna de las instalaciones cuenta con señalamientos para su localización, incluyendo las cabañas, restaurantes, servicios de embarcaciones, tiendas y demás que operan las cooperativas. Sólo las cabañas de una cooperativa a la orilla de las Lagunas de Chacahua se observaron con un anuncio tipo "espectacular», de tamaño mediano, el cual, no se puede observar desde la carretera por lo que no cumple su función publicitaria.

Asimismo, la publicidad por internet no es usada por ninguna de las cooperativas debido a la falta de habilidades tecnológicas de sus miembros y falta de cobertura de este servicio. Televisión y radio no son usados tampoco debido a los altos precios. En contraparte, los trípticos y volantes impresos son la publicidad más usada por las cooperativas turísticas; sin embargo, este tipo de publicidad está supeditada a que los puestos de promoción turística, ubicados en las playas principales, distribuyan la publicidad ya que los cooperativistas no distribuyen personalmente la publicidad. 
En cuanto a la promoción de cooperativas de servicios turísticos, esta se realiza básicamente a través de promotores independientes que reciben comisiones cuando logran llevar clientes a las cooperativas. Sin embargo, esto no siempre funciona debido a que otras opciones de hoteles privados y de cadenas hoteleras ofrecen comisiones más atractivas a los promotores.

Sobre la necesidad de un medio de publicidad y promoción alterno, Luis Antonio Fuentes, Secretario de la Cooperativa "Lagarto Real» menciona que "otra de las situaciones que nosotros tenemos es la falta de promoción directa. Necesitamos algún tipo de promoción pero diferente, nosotros no nos metemos mucho con volanteo ni nada de eso porque al final de cuentas mucha gente no lo lee, a veces es muy poca y es raro la gente que tiene la costumbre de leer un folleto». Sobre las consecuencias de la falta de publicidad de las diversas cooperativas de la Región, la misma persona señala que «hay muchas cooperativas que tienen 15 o 20 años que ahí están y que realmente no prestan ningún servicio porque nadie las visita».

\subsection{Niveles bajos de capital social}

El capital social se puede definir como las relaciones, valores, actitudes y acciones de solidaridad, confianza y cooperación que prevalecen en un grupo social y que pueden ser usadas para enfrentar y resolver problemas comunes (Sosa y Bush, 2017). Existen estudios que señalan la estrecha relación entre niveles altos de capital social y el éxito de las cooperativas y los emprendimientos sociales, relacionando teóricamente este activo social con facilitar la toma de decisiones y la cooperación en las cooperativas en una región (Bretos, Díaz-Foncea, Marcuello y Marcuello, 2018). Sobre su composición, algunos estudiosos del tema identifican hasta doce dimensiones que componen el capital social, pero la gran mayoría reconoce que la confianza es la dimensión principal de este activo social. En el caso de México, según lo reportado por la «World Value Survey» (WVS Association, 2015) los niveles de capital social son bajos comparados con el promedio de los países del Continente Americano. En la Región estudiada, la dimensión «acción colectiva» parece ser más fuerte pues existe la tradición de realizar trabajo comunitario denominado tequio. Asimismo, se reporta que las comunidades se han organizado para enfrentar exitosamente enemigos comunes como la presencia del crimen organizado y los intentos de privatización de playas. Sin embargo, la dimensión de «confianza interpersonal» se observa insuficiente en las cooperativas ante el reto de manejar recursos finan- 
cieros colectivos, sobre todo cuando se combina la gran precariedad económica de los socios con la recepción de cuantiosos apoyos gubernamentales. Con relación a esto, Consuelo Mujica Hernández, Secretaria del Consejo de Vigilancia de la Cooperativa Turismo Alternativo Tututepec y Secretaria de la Red Lagunas de Chacahua, explica que «Mientras no hay dinero estamos tranquilos, pero cayendo un goterito se arma la Troya. Por ambición y necesidad, por la necesidad de que a veces no tiene uno nada y la ambición de que de repente ve uno mucho, pueden ser las dos cosas». En el mismo sentido, Fidel Oliva Ruiz, tesorero de la Cooperativa El Lagartero Tututepec, menciona que «el problema es cuando empieza a llegar el recurso y ahi es donde empieza la gente el pleito, porque quieren dinero, no quieren trabajar pero quieren dinero, empiezan a pelear por el dinero, no es otra cosa». Confirmando esta problemática, Lucia Santos López, presidenta de la Cooperativa Flama Extraña, señala que "Es cuando ya tiene dinero la cooperativa, cuando ya empiezan las dificultades, que ya no anda nada bien, que ya cada quien quiere jalar por su lado, el dinero lo quisieran manejar todos... cuando hay dinero ya empiezan a pelear».

\subsection{Otras áreas de oportunidad estudiadas}

Otras áreas de oportunidad que se estudiaron pero que no se encontró evidencia de ellas son las siguientes: a) Isomorfismo: entendido como el hecho de que una empresa privada, asuma la forma jurídica de cooperativa para aprovechar los apoyos gubernamentales hacia este tipo de organizaciones, sin ser realmente una empresa social. Sólo se detectó un caso y no se incluyó en las cooperativas estudiadas por ser una cooperativa en proceso de formación. El resto de las cooperativas no presentan evidencia de este fenómeno. b) Competencia desleal con empresas privadas: En algunos municipios de la Región no se ha permitido la instalación de cadenas hoteleras como es el caso de «Puerto Escondido» y los hoteles privados no tienden a ser grandes y lujosos por lo que la competencia en ese lugar no puede catalogarse como desleal. En el caso de las «Bahías de Huatulco», donde existen grandes hoteles y cadenas, los cooperativistas consideran que la competencia no es directa pues ellos atienden al turismo nacional e internacional de playa y de convenciones, mientras las cooperativas buscan atender al turismo alternativo.

Como se puede apreciar, las deficiencias o áreas de oportunidad que presentan las organizaciones estudiadas son muy diversas y recurrentes, lo cual explica la alta mortalidad de las mismas. Algunas de las causas 
estratégicas de fondo que podrían intuirse a partir de revisar la literatura actual, se abordan en el siguiente apartado.

\section{Causas sistémicas de la morbilidad y áreas de oportunidad encontradas}

Las áreas de oportunidad descritas anteriormente producen una serie de efectos que limitan totalmente el desempeño de las cooperativas de la Región, generando un proceso progresivo de descomposición en las dimensiones social, económica, administrativa, financiera y técnica. Esto, determina finalmente su quiebra o desintegración real. Entre los síntomas o consecuencias que prevalecen en las cooperativas estudiadas se pueden mencionar: bajas ventas e ingresos; desconocimiento de la situación financiera de la organización; falta de liquidez; empobrecimiento de los socios; dependencia financiera; venta de activos; subordinación a las organizaciones de segundo piso; informalidad; proyectos productivos inconclusos; mala imagen de la economía social; destrucción del capital social comunitario; desorganización; baja competitividad; frustración y desánimo de los socios; abandono de la organización; alta mortalidad de las cooperativas.

Es importante señalar que estos efectos o síntomas no se deben confundir con las mismas áreas de oportunidad, ni con las causas estratégicas de fondo. Se deben separar los tres conjuntos por ser las causas estratégicas las que deben atenderse para resolver de raíz el problema de la mortalidad cooperativa en la Región. En ese sentido, se recurrió a la lógica del «método genético» ${ }^{6}$ de investigación; misma lógica que soporta la herramienta del «árbol de problemas» que se presenta en la figura No. 1 donde se separan los tres grupos de elementos.

A partir de la revisión de la literatura actual sobre Gestión y Administración Pública7, así como sobre economía y sociología, se identificaron seis causas estratégicas de fondo, que indudablemente deben confirmarse o negarse con estudios posteriores, las cuales se explican brevemente a continuación:

6 El método genético en investigación se entiende como una aproximación a los fenómenos de la realidad a partir de considerar los procesos y factores que lo determinan o le dan origen, buscando así identificar las causas de fondo, los hechos o fenómenos con sus diversas características y sus consecuencias o efectos (Rodríguez y Pérez, 2017)

7 En este caso se utilizaron el «Enfoque Neo-institucional», el «Enfoque de Sistemas», la «Nueva Gestión Pública» y el «Enfoque de Administración Estratégica», para mayor información se puede consultar Shafrytz y Hyde (1999). 
a) Excesiva precariedad económica de los socios cooperativistas de la Región

México es considerado uno de los países donde más ha crecido la pobreza y vulnerabilidad en las últimas décadas. Hasta el año 2018, cuando concluye el último gobierno neoliberal, se contabilizaron 52.4 millones de mexicanos en pobreza y pobreza extrema, además de 45.3 millones en vulnerabilidad por ingresos o carencias sociales; en total 97.7 millones (78.1\%) de habitantes en condiciones de pobreza o vulnerabilidad (CONEVAL, 2018). La situación en la Costa de Oaxaca es aún más grave por ser una de las regiones de mayor pobreza y vulnerabilidad del país. En esta Región, los socios cooperativistas destacan por su precariedad económica lo que los lleva a organizarse en cooperativas para tratar de obtener ingresos.

La precariedad económica, aunada a la incertidumbre de no lograr la sostenibilidad de la cooperativa y obtener así beneficios económicos de largo plazo, lleva a los socios a la desesperación, explicando así la actitud calificada de "oportunista y ambiciosa» en la que caen cuando reciben cuantiosos recursos de apoyo gubernamental. La precariedad económica los obliga a centrar su atención en las necesidades inmediatas y no en el largo plazo que se les presenta lleno de incertidumbre. Esto nos lleva a plantear que debiera existir un piso mínimo de bienestar para lograr que las políticas de apoyo a la economía social sean efectivas. Esto ya ha sido planteado por otros autores como Guarnizo (2011).

b) Política educativa alienada, sin programas académicos para la economía social

Recientemente en el ámbito académico se ha empezado a cuestionar la efectividad de la educación en sus diferentes niveles. Para algunos autores como Vallaeys (2006), los programas académicos universitarios de muchos países no se interesan, ni difunden, conocimientos útiles para lo que podríamos llamar la economía real, o según Max Kneef, Elizalde y Hopenhayn (2006) Economía a Escala Humana. Se plantea que la educación formal no está teniendo los impactos esperados en cuanto a que desarrolle en los estudiantes las capacidades para enfrentar las exigencias de la vida real. Por ejemplo, en México es de conocimiento común que la educación universitaria en las áreas de Gestión y Administración se centra en la enseñanza de teorías, metodologías, técnicas y herramientas diseñadas 
específicamente para las grandes corporaciones y no para las micro, pequeñas y medianas empresas (MiPymes), privadas o sociales, que son las que sustentan más del $90 \%$ del empleo del país. Se puede afirmar entonces que existe una desvinculación entre la educación formal, en todos los niveles, principalmente el superior, con su entorno y por tanto con las economías alternativas como la social, la solidaria, la popular, la familiar y el bienestar. De la misma manera, la educación básica y media no proporciona conocimientos para que los individuos puedan cultivar, construir, producir, gestionar, comercializar y agregar valor a la producción por sí solos; es decir no les proporciona conocimientos para la autogestión y la autoproducción que es lo que se requiere en regiones como la Costa de Oaxaca. Esto mismo sucede en otras regiones del mundo según lo señala Martín, et al (2013). Una crítica más contundente la realizan Max Kneef (2014) y Galaaz y Prieto (2006), señalando que el sistema educativo sólo contribuye a formar empleados u obreros para un mercado laboral pauperizado, en franco detrimento o inexistente en muchas regiones. De esta forma, se confunde el propósito final de la educación que es el de la emancipación del hombre y de la vida, con el de la formación de recursos humanos baratos al servicio de la reproducción del capital.

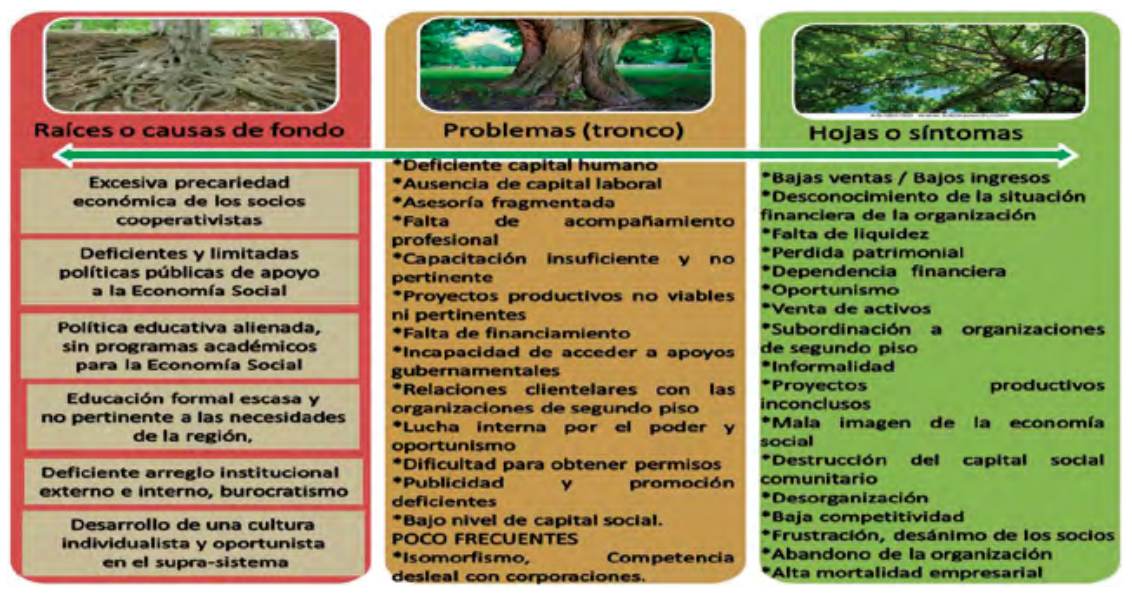

Fuente: Elaboración propia con base en entrevistas, encuesta, observación y revisión bibliográfica.

Figura N. ${ }^{\circ} 1$

Árbol de Problemas de las Cooperativas de la Región de la Costa de Oaxaca, México. 


\section{c) Deficiente arreglo institucional externo e interno}

Las instituciones se entienden como las reglas del juego que regulan la interacción social entre los diversos actores de un sistema determinado (Ayala, 2001), en este caso el sistema cooperativista. Alarcón (2016) define las instituciones como «los usos, hábitos, reglas, rutinas, costumbres o normas por los que se rigen las relaciones sociales y económicas entre los miembros de un grupo». El arreglo institucional es el conjunto de reglas o normas «formales e informales ${ }^{8}$ que limitan y dan orden a las interacciones o transacciones sociales (Powell y Dimaggio, 1999). Un arreglo institucional adecuado o eficiente es el que asegura la cooperación entre los diversos actores involucrados en un sistema, de tal manera que todos resulten beneficiados a través de establecer la «alineación de intereses» donde cada actor pueda obtener su beneficio personal, "si y sólo si, y en la medida que contribuya al beneficio colectivo» (Sosa, Gómez, Rodríguez y Sánchez, 2016: 111). En este caso, el beneficio colectivo es el que deben recibir las cooperativas y sus socios por ser quienes proporcionan la razón de ser del sistema en su totalidad. Asimismo, el marco normativo que regula las cooperativas debería proveer las bases para su reproducción y desarrollo, sin embargo, en el caso de México, este conjunto de normas pone en riesgo la autonomía de las cooperativas, supeditándolas al interés de actores externos (Izquierdo, 2019). En la Región estudiada, la motivación de los gestores externos (facilitadores y Redes o Federaciones de Cooperativas) en la obtención del apoyo gubernamental y no así en el desarrollo futuro de las cooperativas, manifiesta claramente la "falta de alineación de intereses», un fenómeno que parece ser muy común en las políticas públicas impulsadas en México y gran parte del mundo. En cuanto al arreglo institucional interno, entendido como el agregado de reglas formales e informales que regulan la interacción social al interior de cada organización (Murillo, González y García: 2010), se observa que en las cooperativas estudiadas prevalece también la falta de alineación de intereses ya que al en-

8 Las leyes, decretos, manuales, reglas de operación y otros documentos oficiales que conforman las políticas públicas de apoyo al sistema cooperativista se podrían entender como las «normas formales»; mientras que los comportamientos repetitivos derivados de la cultura, las preferencias sociales y los usos y costumbres de los actores, se pueden considerar las «normas informales». Para los neo-institucionalistas las normas informales pueden modificarse en el mediano plazo a través de un rediseño radical de las normas formales. A esto le llaman «reingeniería institucional» (Ayala, 1999 y 2001) 
trar en un proceso de crisis de la cooperativa, algunos socios buscan su beneficio personal, procurando apropiarse de los activos fijos, en lugar de canalizar su creatividad en el rescate y desarrollo de la cooperativa. Los funcionarios públicos también se ocupan únicamente en cumplir con metas específicas dentro del programa o política pública que les corresponde, sin darle la debida importancia a la viabilidad futura de las cooperativas.

d) Deficientes y limitadas políticas públicas de apoyo a la economía social

Como se puede observar, muchas de las deficiencias de las cooperativas estudiadas se originan por las características de las políticas gubernamentales de apoyo. En primer lugar, los recursos asignados son insuficientes para cubrir las necesidades de las cooperativas, además de que su ejercicio es muy lento y complejo lo que repercute en atrasar el suministro de recursos a los beneficiarios. Sin embargo, existen otras deficiencias más importantes como la falta de un sistema de indicadores de gestión que incluya mediciones periódicas de eficiencia, eficacia, calidad, impacto, entre otros, que apoyen la evaluación y el rediseño de las políticas respectivas. Por otra parte, como ya se mencionó, si una política pública no logra «alinear intereses» entre los actores involucrados, está condenada a no generar los impactos necesarios. Por lo menos eso afirman los neo-institucionalistas (Ben-Ner y Putterman, 1999), (Ayala, 2001). Además, existen estudios que confirman que los arreglos institucionales eficientes y la alineación de intereses son indispensables para el éxito de las políticas públicas (Sosa, et al., 2016) (Powell y Dimaggio, 1999). La política pública de apoyo a la economía social en México, supone de antemano los intereses y el comportamiento que «debieran» tener los diversos actores involucrados en el sistema (autoridades y funcionarios, socios cooperativistas, proveedores, organizaciones de segundo piso, entre otros), determinando así las reglas de operación, manuales, leyes y demás instrumentos normativos de los programas respectivos. Sin embargo, como se ha expuesto, los intereses y los comportamientos reales de los actores difieren de lo «ideal» y por tanto los resultados e impactos no favorecen el propósito de la política pública. Este fenómeno es denominado en el ámbito académico como «juego sucio» y ocurre cuando las reglas de operación de los programas gubernamentales permiten que algún o algunos actores (en este caso los facilitadores externos y las organizaciones cooperativas de segundo 
piso) obtengan su beneficio sin contribuir necesariamente al propósito formal del programa. De esta manera, aunque se cumpla con los procesos formalmente establecidos, al final los impactos no son los esperados ya que al dejar de lado los intereses reales de los actores involucrados, todo se convierte en una «simulación» de búsqueda del propósito formal de la política o programa público. Finalmente, la escasa preparación de los funcionarios y autoridades involucradas, la falta de información veraz, clara, oportuna y suficiente para orientar la toma de decisiones y la ausencia de dialogo entre beneficiarios y gobierno, terminan erosionando cualquier posibilidad de éxito de la política de apoyo a la economía social.

\section{e) Desarrollo de una cultura individualista y oportunista en el supra- sistema}

Para algunos estudiosos de la sociología como Bejar (1989) y Cienfuegos, Saldivar, Díaz y Ávalos (2016), el ser humano tiende a ser por naturaleza cooperativo y honesto; sin embargo, el supra-sistema en que se desenvuelve, compuesto por la cultura, las normas oficiales, la educación formal, los medios de comunicación masiva, entre otros; alteran su percepción sobre la importancia de la cooperación, la honestidad y el interés colectivo y por tanto modifican su comportamiento. De esa forma, a partir de la segunda mitad del siglo pasado y especialmente durante el período neo-liberal, se ha ido construyendo, de manera muy efectiva, una cultura individualista y oportunista que resulta totalmente perjudicial para el sistema cooperativo que se fundamenta en la colaboración, el beneficio mutuo, la honestidad y la transparencia. Esto ha repercutido en la disminución drástica de los niveles de capital social de la mayor parte de países del mundo, incluyendo países desarrollados como Estados Unidos y países en vías de desarrollo como México (Sosa y Bush, 2017). Este capital social, se puede considerar el gran sustento del sistema cooperativista y por tanto su disminución perjudica drásticamente al mismo. De esta forma, el desarrollo de una cultura individualista y oportunista, provoca que se pierdan cada vez más los «fines solidarios, de equidad y justicia social» del sistema cooperativista, así como el sentido estricto del concepto de cooperación que «significa trabajar juntos y al trabajar juntos, hacerlo igualitariamente sin diferencia alguna» (Rivera y Labrador, 2013:3). Se puede decir por tanto que esto es una de las principales causas del fracaso del sistema cooperativo en México y probablemente en el mundo. 
f) Educación formal escasa y no pertinente a las necesidades de la región

Como ya se ha señalado en este trabajo, el nivel de escolaridad formal de los cooperativistas de la Región es muy bajo, el 75\% de ellos tienen un grado de escolaridad formal de secundaria o menos. Esto los imposibilita a enfrentarse a la complejidad de un emprendimiento productivo social o privado. Un porcentaje reducido de los cooperativistas tiene educación técnica o universitaria (8\%); sin embargo, la ausencia de contenidos académicos vinculados a los emprendimientos sociales o privados, la autoproducción y la autogestión, provoca que prácticamente toda la población, incluyendo técnicos y universitarios, sean incapaces de realizar de manera cabal y exitosa un emprendimiento social. En el caso de México, se debe tener en cuenta que alrededor del $60 \%$ de la población económicamente activa ocupada se encuentra en la informalidad laboral (INEGI, 2018) y que existen 9.3 millones de personas con licenciatura o posgrado que viven en condiciones de pobreza (Reyes, 2018). Esto denota la falta de efectividad del sistema educativo, pero sobre todo la falta de pertinencia de sus contenidos programáticos, pues la gran mayoría de estos (sino es que la totalidad) buscan desarrollar competencias únicamente para el mercado laboral vinculado a la economía formal u oficial, pero casi ninguno desarrolla capacidades para las economías alternativas como la informal, social, solidaria y cooperativa, entre otras. Considerando que únicamente alrededor del $30 \%$ de la PEA trabaja en el sector formal, la educación debería enfocarse a desarrollar competencias para el emprendimiento privado y social, la autoproducción y la autogestión que apoyen las economías alternativas. Algunas universidades recientemente han incluido en sus programas la impartición de cursos sobre emprendimiento pero los intentos son aún mínimos y precarios. En otras regiones del mundo ya se ha tomado conciencia sobre la necesidad de la educación en emprendimiento social y privado. Un ejemplo a resaltar es el hecho de que «el 23 de mayo de 2017 los Gobiernos de 11 países de la UE firmaron la "Declaración de Madrid", en la que destacan la pertinencia de fomentar e incluir el emprendimiento bajo fórmulas de la economía social dentro de los planes de estudio en las diferentes etapas educativas» (Sánchez, et al., 2018:16); sin embargo en México esto está prácticamente olvidado a pesar del fracaso del modelo económico hegemónico y del crecimiento desmesurado de la pobreza y la marginación en las últimas décadas. 


\section{Conclusiones generales}

Las cooperativas de la Región de la Costa de Oaxaca en México, presentan una diversidad de problemas o áreas de oportunidad en las dimensiones administrativa, económica, social, técnica e incluso política. Estas áreas de oportunidad impactan negativamente el desempeño de las cooperativas llevándolas paulatinamente a un proceso de desintegración y desmantelamiento del que son víctimas casi todas.

Las áreas de oportunidad o problemas que afectan a estas cooperativas son, principalmente: 1) Deficiente capital humano y ausencia de capital laboral; 2) Asesoría fragmentada y falta de acompañamiento profesional; 3) Capacitación insuficiente y no pertinente a las necesidades de las cooperativas; 4) Proyectos productivos no viables ni pertinentes desde el punto de económico y técnico; 5) Falta de financiamiento e incapacidad de acceder a apoyos gubernamentales; 6) Relaciones clientelares con las organizaciones de segundo piso; 7) Lucha interna por el poder y oportunismo; 8) Dificultad para obtener permisos de operación; 9) Publicidad y promoción deficientes; 10) Bajos niveles de capital social.

Los anteriores problemas generan una serie de consecuencias o síntomas que son muy evidentes en las cooperativas estudiadas, entre estos síntomas destacan: bajas ventas e ingresos; desconocimiento de la situación financiera de la organización; falta de liquidez; empobrecimiento de los socios; dependencia financiera; venta de activos; subordinación a las organizaciones de segundo piso; informalidad; proyectos productivos inconclusos; mala imagen de la economía social; destrucción del capital social comunitario; desorganización; baja competitividad; frustración y desánimo de los socios; abandono de la organización; repercutiendo finalmente en alta mortalidad de las cooperativas.

Sin embargo, más allá de describir los problemas que enfrentan las cooperativas e identificar los síntomas o consecuencias, lo cierto es que resulta apremiante encontrar las causas estratégicas de fondo para plantear soluciones viables que permitan el rediseño de las políticas públicas y la emancipación del movimiento cooperativista en la Región y en el país.

A partir de la revisión de la literatura disponible sobre administración, economía y sociología se pueden identificar seis causas estratégicas de fondo de los problemas encontrados, las cuales son: a) Excesiva precariedad económica de los socios cooperativistas; b) Política educativa alienada, sin programas académicos para la economía social; c) Deficiente arreglo institucional externo e interno; d) Deficientes y limitadas políticas públicas de apoyo a la economía social; e) Desarrollo de 
una cultura individualista y oportunista en el supra-sistema; f) Educación formal escasa y no pertinente a las necesidades de la región.

Considerando lo anterior, se puede afirmar que el entorno social, educativo, jurídico, institucional, económico e incluso político (por las políticas públicas existentes), conforman un supra-sistema o entorno que es totalmente adverso al cooperativismo. Este entorno, por un lado, financia los emprendimientos sociales $y$, por el otro, ahoga lentamente a las organizaciones cooperativas producto de esos emprendimientos. Se puede hablar entonces de una determinación sistémica del fracaso de las cooperativas en la Región de la Costa de Oaxaca y probablemente en todo México. El entorno determina finalmente el desempeño de las cooperativas y termina llevándolas al fracaso. De esta forma, se contribuye a estigmatizar la economía social, específicamente al cooperativismo y por tanto a reafirmar en la sociedad la idea equivocada de que no existe otro tipo de economía posible fuera del modelo hegemónico.

Se debe tener presente que el cooperativismo y la economía social representan opciones exitosas en diversos países y actualmente se convierten en opciones más necesarias ante la crisis del modelo económico hegemónico. Se debe reconocer que es el entorno adverso en México y la Región de estudio el que ahoga el cooperativismo y sus organizaciones pues, en varios países con cultura y economía similar, el cooperativismo ha tenido un papel destacado en la solución de las grandes necesidades y retos que enfrenta la sociedad. Se deben atender las causas estratégicas de fondo del fracaso de las cooperativas para asegurar el surgimiento, desarrollo y éxito de estas organizaciones que constituyen un tipo de economía más humana, justa y sustentable, que coloca a las personas, el bienestar social, la ecología y la vida misma por encima del reducido concepto del lucro financiero del modelo económico hegemónico.

\section{Referencias}

ABIÉTAR, M., ROS-GARRIDO, A. y MARHUENDA, F. 2018. «Profesionales de apoyo a la inserción: formación y acompañamiento en empresas de inserción». CIRIEC-España, Revista de Economía Pública, Social y Cooperativa, 94: 155-183, DOI: 10.7203/CIRIEC-E.94.12698.

AGUILAR, J., ALTAMIRANO, J., REYES, L. y RENDÓN, R. 2010. Del extensionismo agrícola a las redes de innovación rural. 1a ed. México: Universidad Autónoma de Chapingo.

ALARCÓN, M.A. 2016. «La economía social desde el institucionalismo económico. Evidencia empírica». CIRIEC-España, Revista de Economía Pública, 
Social y Cooperativa, 86: pp. 61-100. Acceso el 15 de febrero de 2019. https://ojs.uv.es/index.php/ciriecespana/article/view/8167/11531

ALIANZA COOPERATIVA INTERNACIONAL ACI. 2018. Cifras y Datos. Acceso el 20 de febrero de 2019. https://www.ica.coop/es/cooperativas/datos-ycifras.

ARNOLETTO, Eduardo Jorge. 2009. «Cultura, clima organizacional y comportamiento humano en las organizaciones». Folletos Gerenciales, Año XIII, No. 1, pp. 70-86. Acceso el 15 de marzo de 2019. https://www.academia.edu/1308542/CULTURA_CLIMA_ORGANIZACIONAL_Y_COMPORTAMIENTO_HUMANO_EN_LAS_ORGANIZACIONES

AYALA ESPINO, José. 1999. Instituciones y economía. Una introducción al neoinstitucionalismo económico. México: Fondo de Cultura Económica (FCE).

AYALA ESPINO, José. 2001. Economía del sector público mexicano. Primera edición, México: Esfinge.

BEN-NER, Avner y Louis PUTTERMAN. 1999. «Valores e instituciones en el análisis económico». CIRIEC, Revista de Economía Pública, Social y Cooperativa, No. 33, pp. 43-78. Acceso el 15 de marzo de 2019. https://www. researchgate.net/publication/4815021_Valores_e_instituciones_en_el_analisis_economico

BÉJAR, Helena. 1989. La cultura del individualismo. Reis, No. 46, pp. 51-80. DOI: $10.2307 / 40183393$

BOBBIO, Norberto, MATTEUCCI, Nicola y PASQUINO, Gianfranco. 2013. Diccionario de política, México: Siglo XXI.

BRETOS, Ignacio, Millan DÍAZ-FONCEA, Chaime MARCUELLO, y Carmen MARCUELLO. 2018. "Cooperativas, capital social y emprendimiento: Una perspectiva teórica». REVESCO. Revista de Estudios Cooperativos, No. 128, pp. 76-98. DOI: http://dx.doi.org/10.5209/REVE.59775.

BUNGE, Mario. 2008. Filosofía y Sociedad. 1. a edición. México: Siglo XXI.

CIENFUEGOS-MARTÍNEZ, Yessica IVET, Alicia SALDÍVAR, Rolando DÍAZ y Alejandro AVALOS. 2016. «Individualismo y colectivismo: caracterización y diferencias entre dos localidades mexicanas». Acta de investigación psicológica, 6(3): 2534-2543. https://dx.doi.org/10.1016/j.aipprr.2016.08.003

CALDENTEY, Pedro. 2004. Comercialización de Productos Agrarios. Primera edición, México: Mundi Prensa.

CIRUELA LORENZO, Antonio. 2009. "La formación del capital humano como elemento de desarrollo de las cooperativas: Análisis de las necesidades formativas en las sociedades cooperativas mediante procesos de auditoría sociolaboral». CIRIEC-España, Revista de Economía Pública, Social y Cooperativa, No.64, pp. 85-104. Acceso el 15 de marzo de 2019. http:// ciriec-revistaeconomia.es/wp-content/uploads/6404_Ciruela.pdf

CONEVAL CONSEJO NACIONAL DE EVALUACIÓN DE LA POLITICA SOCIAL. 2018. Medición de la Pobreza en México (2010-2018). Acceso el 15 de marzo de 2019. https://www.coneval.org.mx/Medicion/MP/Paginas/Pobreza-2018.aspx .

DAVIS, Keith y JOHN NEWSTRON, J. 2002. El comportamiento humano en el trabajo. Octava edición, México: Mc Graw Hill. 
GALAZ, Caterine y Rodrigo PRIETO. 2006. Economía solidaria: de la obsesión por el lucro a la redistribución con equidad. Barcelona: Icaria.

GALLEGO-BONO, Juan R. y TAPIA-BARANDA, María R. 2019. «Los valores de la economía social como impulsores del cambio en clústeres con fuerte fragmentación del conocimiento: el caso de la caña de azúcar de Veracruz (México) »., CIRIEC-España, Revista de Economía Pública, Social y Cooperativa, 97, 75-109. DOI: 10.7203/CIRIEC-E.97.14108.

GUARNIZO, Carlos. 2011. Modelando el genoma social. Un nuevo paradigma de gestión sistémica de la complejidad y el caos para el desarrollo humano integral. Lima, Perú: Carlos A. GUARNIZO OLIVERA. Acceso el 15 de marzo de 2019. https://www.tendencias21.net/libros/attachment/427961/

GUTIÉRREZ OCHOA, Francisco; Luis Sergio SOSA GONZÁLEZ y Mario Miguel CARRILLO HUERTA. 2015. Análisis del capital social en la Costa de Oaxaca. Revista Desarrollo Local Sostenible, N. ${ }^{\circ} 23$, Vol. 8, pp.1-16. Acceso el 15 de marzo de 2019. www.eumed.net/rev/delos/23

INEGI INSTITUTO NACIONAL DE ESTADÍSTICA, GEOGRAFÍA E INFORMÁTICA. 2015. Esperanza de vida de los negocios a nivel nacional y por entidad federativa. Acceso el 15 de marzo de 2019. http://www.beta.inegi.org.mx/ temas/evnm/doc/evn_ent_fed.pdf .

INEGI INSTITUTO NACIONAL DE ESTADÍSTICA, GEOGRAFÍA E INFORMÁTICA. 2018. Indicadores de ocupación y empleo: Cifras oportunas durante diciembre de 2018. Acceso el 20 de septiembre de 2019. https://www.inegi. org.mx/contenidos/saladeprensa/boletines/2019/iooe/iooe2019_01.pdf

IZQUIERDO MUCIÑO, Martha. 2019. «Problemas en las cooperativas mexicanas que atentan contra el principio de autonomía e independencia»». Boletín de la Asociación Internacional de Derecho Cooperativo, Núm. 55, pp.35-54. Acceso el 15 de febrero de 2020. DOI: : http://dx.doi. org/10.18543/baidc-55-2019pp35-54

IZQUIERDO MUCIÑO, Martha. 2017. «La adhesión voluntaria e identidad cooperativa en las empresas cooperativas mexicanas»). Boletín de la Asociación Internacional de Derecho Cooperativo, Núm. 51, pp. 21-44. DOI: http://dx.doi.org/10.18543/baidc-51-2017pp21-44

IZQUIERDO MUCIÑO, Martha. 2013. «El cooperativismo, una opción viable para México». Boletín de la Asociación Internacional de Derecho Cooperativo, Núm. 47, pp. 95-109. DOl: http://dx.doi.org/10.18543/baidc-47-2013pp95-109

KLIKSBERG, Bernardo. 2002. Hacia una economía con rostro humano. Buenos Aires: Fondo de Cultura Económica.

KLIKSBERG, Bernardo. 2012. "Economía Social». El Informe Kliksberg. Acceso el 15 de julio de 2019. http://www.bernardokliksberg.com/series-de-tv/14economia-social/

KLIKSBERG, Bernardo y Dalia SILBERSTEIN. 2015. Responsabilidad social en acción. El ejemplo de los emprendedores sociales. Buenos Aires: Fundación Observatorio de Responsabilidad Social.

MAX KNEEF, Manfred., Antonio ELIZALDE y Martín HOPENHAYN. 2006. Desarrollo a escala humana: conceptos, aplicaciones y algunas reflexiones. Tercera edición, Barcelona: Icaria. 
MAX KNEEF, Manfred. 2014. La economía desenmascarada: del poder y la codicia a la compasión y el bien común. Primera edición, Barcelona: Icaria. ISBN 978-84-9888-557-6.

MARTíN LÓPEZ, Sonia; Josefina FERNÁNDEZ GUADAÑO; Paloma BEL DURÁN y Gustavo LEJARRIAGA PÉREZ DE LAS VACAS. 2013. «Necesidad de medidas para impulsar la creación de las empresas de participación desde los diferentes niveles de enseñanza». CIRIEC-España, Revista de Economía Pública, Social y Cooperativa, No.78, pp.71-99. Acceso el 15 de marzo de 2019. https://www.redalyc.org/pdf/174/17429865006.pdf

MEDINA, Ana Laura y FLORES, Uziel. 2020. « Análisis de la política de desarrollo social en el estado de Oaxaca, México 2013-2016. La economía social como propuesta». Boletín de la Asociación Internacional de Derecho Cooperativo, N. ${ }^{\circ}$ 56, pp.73-105. Acceso el 15 de abril de 2020. DOI http:// dx.doi.org/10.18543/baidc-56-2020pp73-105

MEDINA, Ana Laura y FLORES, Uziel. 2018. «Estudio dialéctico de la economía social». Boletín de la Asociación Internacional de Derecho Cooperativo, N. ${ }^{\circ}$ 52, pp.73-106. Acceso el 15 de julio de 2019. DOI: http://dx.doi. org/10.18543/baidc-52-2018pp73-106

MEDINA, Ana Laura y FLORES, Uziel. 2015. "Análisis de la sociedad cooperativa y su fiscalidad en la región Mixteca Oaxaqueña». Boletín de la Asociación Internacional de Derecho Cooperativo, N. ${ }^{\circ} 49$, pp.251-278. Acceso el 15 de julio de 2019. http://baidc.revistas.deusto.es/article/view/759

MONZÓN, José Luis. 2006. «Economía Social y conceptos afines: fronteras borrosas y ambigüedades conceptuales del Tercer Sector». CIRIEC-España, Revista de Economía Pública, Social y Cooperativa, No.56, pp.9-24. Acceso el 15 de julio de 2019. https://base.socioeco.org/docs/a7405602.pdf

MURILLO, Guillermo; Carlos HERNÁN GONZÁLEZ y Mónica GARCÍA. 2010. Cambio institucional y organizacional: perspectivas teóricas para el análisis. Santiago de Cali, Colombia: Programa Editorial Universidad del Valle.

POWELL, Walter y Paul DIMAGGIO. 1999. El nuevo institucionalismo en el análisis organizacional. México: Coedición CNCP, UAEM, FCE.

REYES, Miguel. 2018. "Los salarios mínimos y la pobreza en México». En HERNÁNDEZ AVENDAÑO, J.L. e IBARRARÁN VINIEGRA, M.A. (coordinadores). ¿Por qué persiste la pobreza y la desigualdad en México? Miradas internacionales y propuesta de política pública. Puebla, México: LupusInquisitor.

RIVERA, Claudio Alberto y Odalys LABRADOR. 2013. «Bases Teóricas y Metodológicas de la Cooperación y el Cooperativismo». Revista Cooperativismo y Desarrollo, Vol 1, No.2. Acceso el 15 de julio de 2019. http://coodes.upr. edu.cu/index.php/coodes/article/view/50/169

ROBBINS, Stephen y Timothy JUDGE. 2013. Comportamiento organizacional. 17 edición, México: Pearson.

RODRÍGUEZ, Andrés y Alipio OMAR PÉREZ. 2017. "Métodos científicos de indagación y de construcción del conocimiento». Revista Escuela de Administración de Negocios, No.82, pp.175-195. https://doi. org/10.21158/01208160.n82.2017.1647 
SÁNCHEZ, Javier; Sonia MARTín LÓPEZ; Paloma BEL DURÁN y Gustavo LEJARRIAGA. 2018. «Educación y formación en emprendimiento social: características y creación de valor social sostenible en proyectos de emprendimiento social». REVESCO. Revista de Estudios Cooperativos, No.129, pp.16-38. DOI: https://doi.org/10.5209/REVE.62492

SHAFRYTZ, Jay y Albert HYDE. 1999. Clásicos de la Administración Pública. México: Coedición CNCPAP; Universidad Autónoma de Campeche; Fondo de Cultura Económica.

SOSA GONZÁLEZ, J.L.S. 2013. El capital social grupal en la agregación de valor: caso productores de amaranto de los municipios de Cohuecan, Puebla y Temoac, Morelos. México: Tesis doctoral Colegio de Posgraduados. Acceso el 15 de julio de 2019 http://www.biblio.colpos.mx:8080/ xmlui/bitstream/handle/10521/1879/Sosa_Gonzalez_JLS_DC_EDAR_2013. pdf? sequence $=1$

SOSA GONZÁLEZ, José Luis Sergio; Sergio ESCOBEDO y Francisco GUTIÉRREZ. 2014. «Relación del capital social y la pertenencia a organizaciones sociales productivas con la agregación de valor». Revista del Observatorio Iberoamericano del Desarrollo Local y la Economía Social, Año 8 - No.16. Acceso el 15 de julio de 2019. https://ideas.repec.org/a/erv/oidles/y2014i162.html

SOSA GONZÁLEZ, José Luis Sergio; Patricio GÓMEZ ABAD; Fabio RODRíGUEZ KORN y Nazareth SÁNCHEZ ROMERO. 2016. «Diagnóstico institucional de políticas y programas de desarrollo: el caso del Proyecto Estratégico de Seguridad Alimentaria en la Sierra Norte del estado de Puebla, México». Revista Teorías, Enfoques y Aplicaciones en Ciencias Sociales TEACS, año 9, número 19, pp.93-112. Acceso el 15 de julio de 2019. https://dialnet.unirioja.es/servlet/articulo?codigo $=6577484$

SOSA GONZÁLEZ, José Luis Sergio y Carrie BUSH. 2017. Capital social en México y Estados Unidos: coincidencias y discrepancias para construir una agenda de investigación. En: Sosa González, J.L.S. y Bush, C.B., (Coords) Capital social en México y Estados Unidos: su relación con la gestión del desarrollo. Madrid, España: Plaza y Valdés España.

SOSA GONZÁLEZ, José Luis Sergio; Patricio GÓMEZ ABAD; José Luis CARMONA y Manuel MEDEL SÁNCHEZ. 2019. "Una aproximación empírica a la viabilidad de los emprendimientos sociales en México: el ciclo de vida de las cooperativas de la Región de la Costa de Oaxaca». REVESCO. Revista de Estudios Cooperativos, No. 131, pp.151-178. DOI: https://doi. org/10.5209/REVE.63564

VALLAEYS, Francois. 2006. Marco teórico de la Responsabilidad Social Universitaria. Lima, Perú: Pontificia Universidad Católica del Perú.

VILLALOBOS, Guadalupe y René PEDROZA. 2009. «Perspectiva de la Teoría del Capital Humano acerca de la relación entre educación y desarrollo económico». Revista Tiempo de Educar, Vol.10 (20), pp.273-306. Acceso el 15 de julio de 2019. https://www.redalyc.org/pdf/311/31112987002.pdf

WVS ASSOCIATION. 2015. World Values Survey (2010-2014). Informe de la Encuesta Mundial de Valores 2010-2014. Acceso el 15 de julio de 2019. http://www.worldvaluessurvey.org/WVSDocumentationWV6.jsp 


\section{ANEXO 1. Cédula de evaluación diagnóstica para cooperativas de producción y/o servicios de la región de la Costa de Oaxaca, México}

Nombre de la cooperativa:

Giro o actividad:

Municipio

Entrevistados (nombre y cargo):

\begin{tabular}{|c|c|c|c|c|c|c|c|c|}
\hline $\begin{array}{c}\text { Área de } \\
\text { oportunidad o } \\
\text { aspecto a evaluar: }\end{array}$ & $\begin{array}{c}\text { Parámetro situación } \\
\text { deficiente (Muy } \\
\text { mal) }\end{array}$ & $\begin{array}{l}\overline{\widetilde{D}} \\
\grave{\Sigma} \\
\stackrel{\Sigma}{\Sigma}\end{array}$ & $\bar{\Sigma}$ & 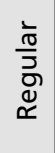 & $\frac{\check{d}}{\infty}$ & $\begin{array}{l}\frac{c}{0} \\
\frac{0}{0} \\
\stackrel{2}{\Sigma}\end{array}$ & $\begin{array}{l}\text { z } \\
\text { ñ } \\
z \\
\text { s }\end{array}$ & $\begin{array}{l}\text { Parámetro situación } \\
\text { ideal (Muy bien) }\end{array}$ \\
\hline $\begin{array}{l}\text { Asesoría y acom- } \\
\text { pañamiento pro- } \\
\text { fesional }\end{array}$ & $\begin{array}{l}\text { No reciben aseso- } \\
\text { ría ni acompaña- } \\
\text { miento por parte } \\
\text { de ningún especia- } \\
\text { lista u organización, } \\
\text { más bien resuelven } \\
\text { sus problemas de } \\
\text { forma empírica. }\end{array}$ & & & & & & & $\begin{array}{l}\text { Cuentan con ase- } \\
\text { soría permanente } \\
\text { y acompañamiento } \\
\text { profesional integral } \\
\text { en temas de finan- } \\
\text { zas, marketing, pro- } \\
\text { ducción y gestión } \\
\text { por parte de especia- } \\
\text { listas comprometidos } \\
\text { con la organización. }\end{array}$ \\
\hline $\begin{array}{l}\text { Capital humano y } \\
\text { capital laboral }\end{array}$ & $\begin{array}{l}\text { La escolaridad o ex- } \\
\text { periencia laboral de } \\
\text { los socios y/o em- } \\
\text { pleados no se re- } \\
\text { laciona con el giro } \\
\text { productivo de la or- } \\
\text { ganización ni con } \\
\text { los emprendimien- } \\
\text { tos sociales. }\end{array}$ & & & & & & & $\begin{array}{l}\text { Tienen socios o em- } \\
\text { pleados con el nivel } \\
\text { y tipo de escolaridad } \\
\text { formal necesario } \\
\text { para enfrentar exi- } \\
\text { tosamente un em- } \\
\text { prendimiento social, } \\
\text { o bien que tienen } \\
\text { experiencia laboral } \\
\text { integral en organi- } \\
\text { zaciones productivas } \\
\text { del mismo giro. }\end{array}$ \\
\hline
\end{tabular}




\begin{tabular}{|c|c|c|c|c|c|c|c|c|}
\hline $\begin{array}{c}\text { Área de } \\
\text { oportunidad o } \\
\text { aspecto a evaluar: }\end{array}$ & $\begin{array}{c}\text { Parámetro situación } \\
\text { deficiente (Muy } \\
\text { mal) }\end{array}$ & 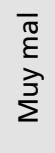 & $\sum^{\bar{\pi}}$ & $\begin{array}{l}\frac{\grave{T}}{5} \\
\frac{\sigma}{0} \\
\check{0}\end{array}$ & $\frac{\widetilde{\sigma}}{\omega}$ & $\frac{\frac{c}{0}}{\frac{0}{a}}$ & $\begin{array}{l}\text { u } \\
\text { ñ } \\
z \\
\text { su }\end{array}$ & $\begin{array}{l}\text { Parámetro situación } \\
\text { ideal (Muy bien) }\end{array}$ \\
\hline $\begin{array}{l}\text { Distribución equi- } \\
\text { tativa de los be- } \\
\text { neficios. }\end{array}$ & $\begin{array}{l}\text { Existen algunos po- } \\
\text { cos que terminan } \\
\text { apropiándose de la } \\
\text { mayor parte de los } \\
\text { beneficios genera- } \\
\text { dos por el trabajo } \\
\text { colectivo (oportu- } \\
\text { nismo). }\end{array}$ & & & & & & & $\begin{array}{l}\text { Los beneficios y uti- } \\
\text { lidades que se gene- } \\
\text { ran en la organiza- } \\
\text { ción se distribuyen } \\
\text { siempre de manera } \\
\text { justa y equitativa de } \\
\text { acuerdo al esfuerzo, } \\
\text { trabajo y aportación } \\
\text { de cada socio. }\end{array}$ \\
\hline Gobernabilidad. & $\begin{array}{l}\text { Existen muchos } \\
\text { conflictos entre } \\
\text { los miembros de } \\
\text { la organización, } \\
\text { los acuerdos se to- } \\
\text { man con mucha di- } \\
\text { ficultad y hay una } \\
\text { pugna constante } \\
\text { por puestos direc- } \\
\text { tivos y por tener el } \\
\text { control de la orga- } \\
\text { nización. }\end{array}$ & & & & & & & $\begin{array}{l}\text { Existe armonía y } \\
\text { confianza entre los } \\
\text { miembros de la or- } \\
\text { ganización, los } \\
\text { acuerdos se toman } \\
\text { sin problemas, los } \\
\text { puestos directivos } \\
\text { son designados por } \\
\text { unanimidad y no } \\
\text { existe una lucha por } \\
\text { el control de la or- } \\
\text { ganización. }\end{array}$ \\
\hline $\begin{array}{l}\text { Trámites burocrá- } \\
\text { ticos y permisos } \\
\text { de operación. }\end{array}$ & $\begin{array}{l}\text { Les ha sido muy di- } \\
\text { fícil y costoso ob- } \\
\text { tener los permisos } \\
\text { necesarios y realizar } \\
\text { trámites en gene- } \\
\text { ral ante las autori- } \\
\text { dades. Aún no han } \\
\text { podido concluir u } \\
\text { obtener algunos de } \\
\text { ellos. }\end{array}$ & & & & & & & $\begin{array}{l}\text { Han podido realizar } \\
\text { sin tantas dificulta- } \\
\text { des los trámites ne- } \\
\text { cesarios ante las au- } \\
\text { toridades y obtener } \\
\text { los permisos de ope- } \\
\text { ración correspon- } \\
\text { dientes, los costos y } \\
\text { el grado de dificul- } \\
\text { tad no han sido muy } \\
\text { altos. }\end{array}$ \\
\hline
\end{tabular}




\begin{tabular}{|c|c|c|c|c|c|c|c|c|}
\hline $\begin{array}{c}\text { Área de } \\
\text { oportunidad o } \\
\text { aspecto a evaluar: }\end{array}$ & $\begin{array}{c}\text { Parámetro situación } \\
\text { deficiente (Muy } \\
\text { mal) }\end{array}$ & $\begin{array}{l}\bar{\pi} \\
\xi \\
\grave{z} \\
\Sigma\end{array} \mid$ & $\sum^{\bar{\pi}}$ & $\begin{array}{l}\frac{1}{0} \\
\frac{\pi}{5} \\
\frac{w}{\alpha}\end{array}$ & $\frac{\widetilde{\omega}}{\omega}$ & $\begin{array}{l}c \\
\frac{c}{0} \\
\frac{a}{2} \\
\Sigma \\
\Sigma\end{array}$ & $\begin{array}{l}z \\
v \\
\Sigma \\
s \\
z\end{array}$ & $\begin{array}{l}\text { Parámetro situación } \\
\text { ideal (Muy bien) }\end{array}$ \\
\hline $\begin{array}{l}\text { Pertinencia y via- } \\
\text { bilidad de proyec- } \\
\text { tos productivos. }\end{array}$ & $\begin{array}{l}\text { El giro o actividad } \\
\text { productiva no coin- } \\
\text { cide con los gustos, } \\
\text { necesidades y de- } \\
\text { manda de los con- } \\
\text { sumidores. No hay } \\
\text { agregación de valor } \\
\text { y la infraestructura, } \\
\text { servicios y ubica- } \\
\text { ción no son atracti- } \\
\text { vos y competitivos. }\end{array}$ & & & & & & & $\begin{array}{l}\text { La actividad produc- } \\
\text { tiva de la organiza- } \\
\text { ción es adecuada a } \\
\text { los gustos, necesida- } \\
\text { des y demanda de los } \\
\text { consumidores, defi- } \\
\text { niendo de manera in- } \\
\text { teligente productos, } \\
\text { servicios, ubicación, } \\
\text { infraestructura y agre- } \\
\text { gación de valor. }\end{array}$ \\
\hline $\begin{array}{l}\text { Apoyos guber- } \\
\text { namentales y de } \\
\text { otros organismos. }\end{array}$ & $\begin{array}{l}\text { No han obtenido } \\
\text { ningún tipo de } \\
\text { apoyo a fondo per- } \\
\text { dido en dinero o } \\
\text { en especie del go- } \\
\text { bierno o de otros } \\
\text { organismos, inde- } \\
\text { pendientemente de } \\
\text { que lo hayan inten- } \\
\text { tado o no. Carecen } \\
\text { de los recursos ne- } \\
\text { cesarios para operar } \\
\text { de forma efectiva. }\end{array}$ & & & & & & & $\begin{array}{l}\text { Han logrado ac- } \\
\text { ceder a cuantiosos } \\
\text { apoyos a fondo per- } \\
\text { dido, en dinero o } \\
\text { en especie, del go- } \\
\text { bierno o de otros } \\
\text { organismos, los que } \\
\text { se han aplicado para } \\
\text { la infraestructura y/o } \\
\text { actividad productiva } \\
\text { de la organización. }\end{array}$ \\
\hline $\begin{array}{l}\text { Publicidad y pro- } \\
\text { moción. }\end{array}$ & $\begin{array}{l}\text { No tienen mecanis- } \\
\text { mos de publicidad } \\
\text { y promoción por lo } \\
\text { que sus productos, } \\
\text { servicios y ubica- } \\
\text { ción no es conocida } \\
\text { por visitantes y po- } \\
\text { sibles clientes de la } \\
\text { región. }\end{array}$ & & & & & & & $\begin{array}{l}\text { Cuentan con meca- } \\
\text { nismos efectivos de } \\
\text { publicidad y promo- } \\
\text { ción que aseguran } \\
\text { que la gran mayoría } \\
\text { de visitantes y po- } \\
\text { sibles clientes de la } \\
\text { región conozcan sus } \\
\text { productos, servicios } \\
\text { y ubicación. }\end{array}$ \\
\hline
\end{tabular}




\begin{tabular}{|c|c|c|c|c|c|c|c|c|}
\hline $\begin{array}{c}\text { Área de } \\
\text { oportunidad o } \\
\text { aspecto a evaluar: }\end{array}$ & $\begin{array}{c}\text { Parámetro situación } \\
\text { deficiente (Muy } \\
\text { mal) }\end{array}$ & 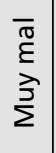 & $\bar{\sum}$ & 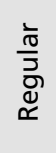 & $\frac{\widetilde{d}}{\oplus}$ & $\frac{\frac{c}{0}}{\frac{2}{0}}$ & $\begin{array}{l}\text { u } \\
\text { vi } \\
z \\
\text { s }\end{array}$ & $\begin{array}{l}\text { Parámetro situación } \\
\text { ideal (Muy bien) }\end{array}$ \\
\hline $\begin{array}{l}\text { Capacitación o } \\
\text { educación coope- } \\
\text { rativa (principios } \\
\text { cooperativos). }\end{array}$ & $\begin{array}{l}\text { No han recibido } \\
\text { ningún curso de } \\
\text { educación coopera- } \\
\text { tiva, no conocen ni } \\
\text { pueden mencionar } \\
\text { los principios coo- } \\
\text { perativos. }\end{array}$ & & & & & & & $\begin{array}{l}\text { Los socios han reci- } \\
\text { bido cursos de edu- } \\
\text { cación cooperativa, } \\
\text { conocen y aplican } \\
\text { permanentemente } \\
\text { los principios coope- } \\
\text { rativos y los explican } \\
\text { fácilmente. }\end{array}$ \\
\hline $\begin{array}{l}\text { Ca pacit ación } \\
\text { para el empren- } \\
\text { dimiento social o } \\
\text { privado. }\end{array}$ & $\begin{array}{l}\text { No han recibido } \\
\text { ninguna capaci- } \\
\text { tación sobre em- } \\
\text { prendimiento social } \\
\text { y/o privado, ni so- } \\
\text { bre planes de ne- } \\
\text { gocios, estudio de } \\
\text { mercado, estudio } \\
\text { técnico, estudio fi- } \\
\text { nanciero, mercado- } \\
\text { tecnia y ventas, ma- } \\
\text { nejo de conflictos, } \\
\text { que son necesarios } \\
\text { para su actividad } \\
\text { empresarial. }\end{array}$ & & & & & & & $\begin{array}{l}\text { Los socios han re- } \\
\text { cibido capacitación } \\
\text { para entender y en- } \\
\text { frentar la compleji- } \\
\text { dad de un empren- } \\
\text { dimiento social y/o } \\
\text { privado, abordando } \\
\text { temas como planes } \\
\text { de negocios, estudio } \\
\text { de mercado, estudio } \\
\text { técnico, estudio fi- } \\
\text { nanciero, mercado- } \\
\text { tecnia y ventas, ma- } \\
\text { nejo de conflictos, } \\
\text { entre otros. }\end{array}$ \\
\hline $\begin{array}{l}\text { Corrupción o des- } \\
\text { vío de fondos. }\end{array}$ & $\begin{array}{l}\text { Se han presentado } \\
\text { casos de corrup- } \\
\text { ción, abuso o des- } \\
\text { vío de recursos que } \\
\text { han perjudicado a } \\
\text { la organización y } \\
\text { han disminuido la } \\
\text { confianza entre los } \\
\text { miembros. }\end{array}$ & & & & & & & $\begin{array}{l}\text { Nunca se han pre- } \\
\text { sentado casos de } \\
\text { corrupción, abuso } \\
\text { o desvío de recur- } \\
\text { sos entre los miem- } \\
\text { bros de la coope- } \\
\text { rativa, prevalece la } \\
\text { confianza y la soli- } \\
\text { daridad en las rela- } \\
\text { ciones. }\end{array}$ \\
\hline
\end{tabular}




\begin{tabular}{|c|c|c|c|c|c|c|c|c|}
\hline $\begin{array}{c}\text { Área de } \\
\text { oportunidad o } \\
\text { aspecto a evaluar: }\end{array}$ & $\begin{array}{c}\text { Parámetro situación } \\
\text { deficiente (Muy } \\
\text { mal) }\end{array}$ & $\begin{array}{l}\bar{J} \\
\varepsilon \\
\widehat{\jmath} \\
\Sigma\end{array}$ & $\bar{\Sigma}$ & $\begin{array}{l}\frac{\grave{\sigma}}{\bar{J}} \\
\underset{\mathscr{d}}{\simeq}\end{array}$ & $\frac{\bar{d}}{\infty}$ & 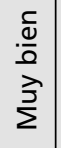 & $\begin{array}{l}u \\
z \\
v i \\
z \\
\dot{z}\end{array}$ & $\begin{array}{l}\text { Parámetro situación } \\
\text { ideal (Muy bien) }\end{array}$ \\
\hline $\begin{array}{l}\text { Evasión de res- } \\
\text { ponsabilidades y } \\
\text { falta de compro- } \\
\text { miso entre los } \\
\text { miembros. }\end{array}$ & $\begin{array}{l}\text { A menudo los } \\
\text { miembros de la or- } \\
\text { ganización no cum- } \\
\text { plen bien con sus } \\
\text { obligaciones y tra- } \\
\text { bajo en la organiza- } \\
\text { ción y es necesario } \\
\text { estar supervisán- } \\
\text { dolos, motivándo- } \\
\text { los o reclamándoles } \\
\text { constantemente. }\end{array}$ & & & & & & & $\begin{array}{l}\text { Normalmente los } \\
\text { miembros son res- } \\
\text { ponsables y entu- } \\
\text { siastas al cumplir } \\
\text { con sus obligaciones } \\
\text { dentro de la organi- } \\
\text { zación. }\end{array}$ \\
\hline $\begin{array}{l}\text { Competencia in- } \\
\text { equitativa con } \\
\text { corporaciones o } \\
\text { grandes empre- } \\
\text { sas. }\end{array}$ & $\begin{array}{l}\text { Existen grandes } \\
\text { empresas y/o pro- } \\
\text { ductos de las mis- } \\
\text { mas con precios, } \\
\text { calidad, publici- } \\
\text { dad, tecnologías o } \\
\text { infraestructura con } \\
\text { las que no es po- } \\
\text { sible competir de } \\
\text { forma exitosa por } \\
\text { sus dimensiones } \\
\text { económicas. }\end{array}$ & & & & & & & $\begin{array}{l}\text { No existen empresas } \\
\text { grandes o productos } \\
\text { de las mismas en la } \\
\text { región con los que } \\
\text { se tenga una com- } \\
\text { petencia directa que } \\
\text { sea inequitativa, im- } \\
\text { posible de enfrentar } \\
\text { o no sana. }\end{array}$ \\
\hline $\begin{array}{l}\text { Otras deficiencias } \\
\text { (explicar): }\end{array}$ & & & & & & & & \\
\hline
\end{tabular}

Siglas: NA=No aplica; NS=No sabe el entrevistado; NC=No contestó el entrevistado. Jlssg-15jul2019 


\section{Derechos de autor}

El Boletín de la Asociación Internacional de Derecho Cooperativo es una revista de acceso abierto lo que significa que es de libre acceso en su integridad inmediatamente después de la publicación de cada número. Se permite su lectura, la búsqueda, descarga, distribución y reutilización legal en cualquier tipo de soporte sólo para fines no comerciales y según lo previsto por la ley; sin la previa autorización de la Editorial (Universidad de Deusto) o el autor, siempre que la obra original sea debidamente citada (número, año, páginas y DOI si procede) y cualquier cambio en el original esté claramente indicado.

\section{Copyright}

The International Association of Cooperative Law Journal is an Open Access journal which means that it is free for full and immediate access, reading, search, download, distribution, and lawful reuse in any medium only for non-commercial purposes, without prior permission from the Publisher or the author; provided the original work is properly cited and any changes to the original are clearly indicated. 